Review Article

www.jestr.org

\title{
State of the Ability in Research on Microgrid Hybrid Energy Systems
}

\author{
Iram Akhtar*, Sheeraz Kirmani and Majid Jamil \\ Department of Electrical Engineering, Faculty of Engineering and Technology, Jamia Millia Islamia, New Delhi-110025, India
}

Received 4 September 2018; Accepted 7 September 2019

\begin{abstract}
The power demand with interest in green power has focused researcher to develop the distributed power generation using wind energy, solar energy, etc. With the fast depleting fossil fuel reserves, energy security and environmental concerns there is a huge requirement of alternate sources of energy to fulfill the present energy demand. Distribution generating system can support the weak grids, maintaining grid power, managing balance power and enhancing the power quality. Any research work base depends on the literature survey and the studies carried out by several kinds of research and their support to research field encourages for more scope of research. The important advantages related to microgrids have led to huge efforts to grow their dispersion in the power systems. While microgrid is fast growing but there are still various challenges to efficiently control, design, and operate microgrids when linked to the main grid, and also when in islanded mode, where wide research actions are ongoing to handle these issues. This paper presents a review of issues concerning integration of renewable energy sources to microgrids and offers a description of research in areas related to economic feasibility of microgrids system, including dynamic analysis of microgrid hybrid system in grid-connected mode, application of power electronics, microgrid operation, and control.
\end{abstract}

Keywords: Distributed generation, DC microgrid, utility grid, economics, operation, and control.

\section{Introduction}

The growing concern about the shortage of energy resources and harmful outcome of fossil fuel emission has initiated a new requirement of reliable and cleaner sustainable energy sources. So, the solar photovoltaic and wind power system is fastest developing sources among the different renewable energy sources. The growth in distributed generation technology, advancement in power electronics circuitry, increase in cost of fuel, energy demand and the depletion of fossil fuel for better stability, reliability and power quality are obliging the power sector to use the renewable energy source as an alternative energy source. Hence, the sustainable microgrid primarily powered by renewable energy sources is recently a conception key to fulfill the pledge to delivering reliable power supply for upcoming power systems. It is a very critical issue to integrate the hybrid energy system to the microgrid and the technical issues related to control, power balance, energy management, and operation varies from one system to another system. The main reasons are to integrate the different numbers, size and nature of renewable energy sources to the microgrid in island mode or grid-connected mode. In grid-connected mode, all parameters must be in the limit otherwise this will damage the system and equipment's connected to the utility grid. Besides, the urgency of the national policy to upgrade the existing coal-based plant as integrated solar, wind and coal-based power plant to reduce the carbon emission and to evaluate the feasibility of developing grid-connected hybrid energy system in different areas need to be investigated. Developing the low carbon

*E-mail address: iraml208@gmail.com

ISSN: 1791-2377 @ 2019 School of Science, HUU. All rights reserved.

doi:10.25103/jestr.125.02 emission plant is a critical issue to cope up with the challenges of global warming. The overall cost of grid-connected hybrid system for residential, industrial and commercial type loads need to be calculated to find a cost-effective solution. Furthermore, the dynamic analysis results provide the guidance for the control method of microgrid hybrid energy system and improvement in the transition between gridconnected and stand-alone mode. Microgrids offer significant benefits for the customers and the utility grid as a whole: improved reliability by introducing self-healing at the local distribution network; higher power quality by managing local loads; reduction in carbon emission by the diversification of energy sources; economic operation by reducing transmission and distribution (T\&D) costs; utilization of less costly renewable DGs; and offering energy efficiency by responding to real-time market prices. A synchronization algorithm for three-phase microgrid application to fast and seamless transform from islanded mode to grid-connected mode can be found in [1]. The microgrid should not track the unbalances and distorted voltage components. Therefore, the sliding Goertzel transform-based filters has been embedded into the PLL- based algorithm to inoculate imbalance grid voltages and settle good power quality supply of the microgrid. The voltage changes between the utility and microgrid should be effectively controlled to understand recombination of microgrid island mode to grid-connected mode. Parallel operation of bidirectional interfacing converters in hybrid $\mathrm{AC} / \mathrm{DC}$ microgrids under unbalanced ac grid situations and proposed a new strategy to improve the power transferability with no power oscillation is discussed in [2]. Parallel operated bidirectional interfacing converters must be kept transferred power constant and no oscillation when grid faults happen. A novel current sharing method has employed which presents modifiable current reference coefficients for parallel operated 
bidirectional interfacing converters. The work focused on unity power factor process of bidirectional interfacing converters. A grid adaptive power management strategy to produce current references for renewable energy system, energy storage system and converted is discussed in [3]. Moreover, these algorithms provide effective load shedding, continuous microgrid operation and confirming the good power quality at local bus. The necessity for energy storage system becomes very important for good operation of sensitive loads. Furthermore, energy storage system needs to be worked within safe charge limits. For the grid system, it is necessary to keep the frequency and voltage within the set limits at local bus under varied situations of loads, grid and renewable energy sources. A robust optimization methodology of microgrid for optimal operation is proposed in [4]. The renewable energy sources inexact output variation is addressed by the direct load control through a two-stage complementary framework and collaboratively scheduling of energy storage. In the robust optimization, the wind speed variation and solar irradiance changes are involved through the indecision sets and the vilest cases specified by the inexact variables are produced and used to make the ultimate solution robust for all the inexact conditions. The approach has been verified on IEEE 33-bus distribution system over a wide range of several tests. Moreover, a supervisory power management system (PMS) for a grid cooperative microgrid with an energy storage system is discussed in [5]. The number of sensors essential to make the PMS have been reduced. The real power transfer between dc microgrid and grid is done by voltage source converter. Moreover, an improved voltage regulation has been achieved and reduces the current stress on the battery. The PMS has addressed risky operation situation such as removal of critical oscillation of energy storage systems power, load shedding and resynchronization with the utility grid. Therefore, novel method of recognizing microgrid operating modes has been proposed and confirmed in all probable operating modes. It was presented that the PMS confirms reliable and uninterrupted power supply to the loads and allows the bidirectional power flow between the utility grid and the microgrid although enhancing the power quality features at the point of common coupling. An optimal energy management method joining interval, sensitivities, and probabilistic uncertainties of solar power and wind power sources and loads in microgrid can be found in [6]. Affine arithmetic has been used to model the interval uncertainties and sensitivities in nodal power injections. Furthermore, the minimization of the operational cost has been taken care by stochastic weight tradeoff particle swarm optimization. The power dispatch intervals and cost are made less conservative with lower reserve requirement, allowing more accurate network operational development.

The rest of the paper is arranged as follows: Section II focuses on the integration of renewable energy sources to microgrid and reviews a variety of issues associated with renewable energy sources and methods to integrate them. Section III discusses the economic feasibility of hybrid energy system comprises of the wind and the solar photovoltaic system, with a focus on wind speed prediction model and the regression models for estimation of global solar radiation. Section IV reviews the dynamic analysis of hybrid system. Section V focuses on intelligent technique-based control of microgrid hybrid energy system with power quality enhancement capabilities. Section VI reviews the DC/DC converters to add the wind and solar sources to the DC microgrid and to improve the system performance. Section VII discusses the challenges ahead in perfecting the performances of grid-connected hybrid energy system Section VIII concludes the paper. To make the discussions regular in the paper, a single representation of concepts/descriptions has been used that can appear in different forms in different papers.

\section{Sustainable Microgrid Primarily Powered By Renewable Energy Sources}

The selection of the electric power system primarily powered by renewable energy sources is based on the requirement and availability of the energy sources. Therefore, there is a need to integrate all the renewable energy sources to the microgrid. Table 1 shows the total installed capacity of India as on $31^{\text {st }}$ May 2019 and Figure 1 shows a similar thing in the form of a pie chart.

Table 1. India's Power at a glance

\begin{tabular}{c|c|c}
\hline Fuel & Power (MW) & $\begin{array}{c}\text { Percentage of } \\
\text { Total }\end{array}$ \\
\hline Thermal & $2,26,279$ & $63.14 \%$ \\
Hydro & 45,399 & $12.7 \%$ \\
Nuclear & 6,780 & $1.9 \%$ \\
Renewable & 78,359 & $22.0 \%$ \\
Energy & & \\
Sources & & \\
\hline
\end{tabular}

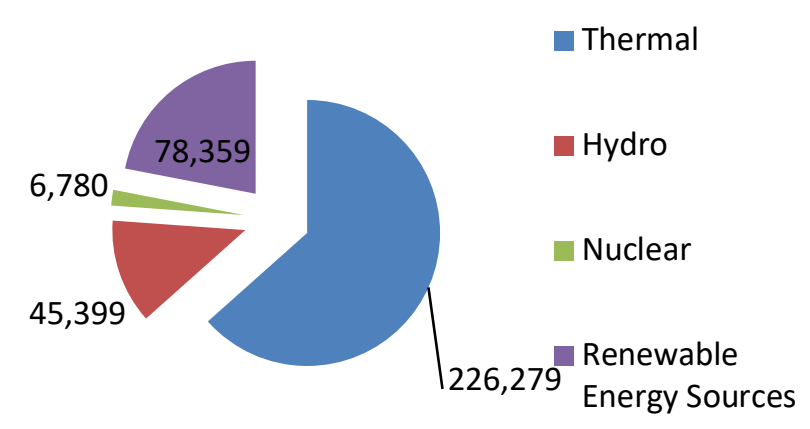

Fig 1. Pictorial representation of India's installed capacity

A microgrid is a group of different interconnected loads and distributed energy resources within evidently defined boundaries that act as a single handy entity with respect to the main grid as shown in fig.1. Depending on the situations, it can be operated either with the main grid or in islanded mode. Micro-sources comprises diesel generators, fuel cells, microturbines, photovoltaic panels, wind turbines, battery etc.

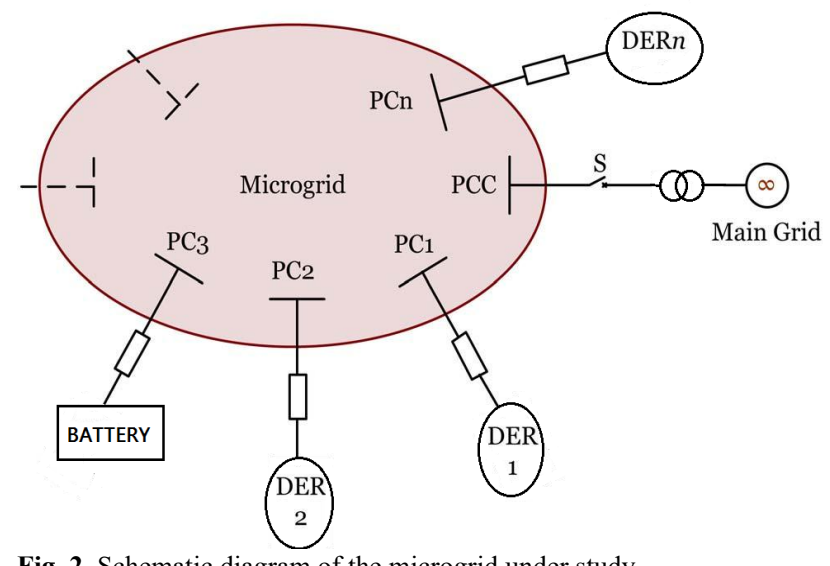

Fig. 2. Schematic diagram of the microgrid under study 
A "Plug and Play" method based on the "System of Systems" viewpoint using distributed control approaches is proposed in [7]. This method permits to interconnect a number of systems to a microgrid as power sources. The offered method can be ascendable to a much larger number of systems. Furthermore, stability analysis is done for the whole system, meanwhile physical restrictions are also considered. Moreover, comparisons with the standard control method are al-so done, showing that the nonlinear controller responds the rapid interconnected turbulences existing in such systems. An experimental execution of a microgrid standalone topology based on brushless generators and voltage source converter is provided in detail in [8]. To keep the reliability of the system, a battery energy storage system (BESS) and a diesel generator (DG) set are used. This topology has benefit of reduced number of switching devices and easy control. The BESS is used at the dc connection to assist the instantaneous power balance under dynamic conditions. The VSC is also used to improve the power quality of the system and mitigate the voltage regulation problem. In [9], a co-optimization approach for renewable energy sources scheduling to reduce the total annual cost with maximum fuel saving is presented. The particle swarm optimization with the Fourier transform, the right combination of renewable energy sources is determined to reduction in the annual cost. A case study to validate the proposed approach for a public microgrid has been presented. The effect of controlling constraints on microgrid growth was also observed. In [10], a sliding mode control based non- linear control method for a renewable energy based microgrid with constant power load is presented. The main aim is to regulate the DC bus voltage and lessen the destabilizing effects of constant power loads. Moreover, an algorithm is employed bidirectional converter which enables three ways charging. The control scheme guarantees preferred operation of the microgrid and keeps system stability with constant power load un-der deviations in the load demand and primary resource. Operation and design optimization has been investigated in [11]. A mixed-integer model is employed form operation from the emission point of view and solar un-certainties are demonstrated by a Markovian process. The entire problem is solved using branch-and-cut and a linear model is recognized to assess the microgrid life- time cost. The main problem is to dispatch distributed devices with green power generation and to minimize the emission cost although meeting the estimated energy demand.

A new adaptive inertia control method with predictive converter control for microgrid to resolve the low inertia difficulty and allow the distributed units to offer adaptive inertia support under disturbance is proposed in [12] According to the features of corresponding micro-sources, adaptive inertia control of wind power system, energy storage system and utility grid is designed. Further-more, a model predictive method is proposed to escape control hysteresis and adjustment error. The inertia response ability is improved by sensibly regulation of the manageable inertia coefficient on every end. Furthermore, three-phase hybrid cascaded modular multi-level inverter topology which is resultant from the improved H-bridge module is presented in [13]. This topology has advantages such as lessening the power switches number, installation area, converter cost, and voltage stress. Furthermore, the comparative study is done using classical cascaded H-bridge and flying capacitor multilevel inverters. To provide the gating signal for the switches, a nearest level control method is used. A simple extremely reliable grid synchronization method based on controller area network communication is proposed in [14]. Microgrids are equipped with the controls essential for handling the operation in the islanded mode or grid connected mode and provide the loads with reliable and uninterruptible power. To minimize the changeover transients, it is essential to synchronize each micro sources with the utility grid. The controller related with micro sources takes the data and permits each micro source to empower grid synchronization.

In [15], A comparative study of three-phase four-wire inverter connection to compensate for negative, positive, and zero sequence components of the current given to the grid has been proposed. The main function of the three-phase inverter is to give power to the utility grid and active power compensation to care unbalance and load neutral current. The connection of single-phase loads and renewable energy sources to the system create the unbalance in the three-phase system. There-fore, three-phase four wire inverter was used to compensate the unbalance locally at the point of common coupling. In [16], home energy management system based on model predictive control for residential microgrid in which every concern information are taken into account such as electricity price, load demand etc. is presented. A new finitehorizon mixed-integer linear programming problem is expressed to examine the optimal control activities of the residential microgrid. Furthermore, a sensitivity investigation is done to prove the advantage of the defined approach when pre-dictions of associated information are flawed. In [17], a model predictive controller for the best loads allocation of a microgrid at an actual operational situation is presented. This design mixes the degradation situations and penalties while considering every components of the hybrid energy storage system and permits to get a best performance of the hybrid system. The results have shown a best performance of the microgrid whose non-dispatchable units are changed into dispatchable units by proper organization of energy storage system. The overcharge and undercharge of the battery can be controlled by hydrogen storage. The battery high-stress current ratio is also reduced with the usage of hydrogen energy storage system. In [18], a multi-objective best compensation method for Multi-functional grid-connected inverters (MFGCI) application. MFGCI provides a power quality improvement facility and interfaces renewable energy sources into the grid is proposed. Hence, additional power quality conditioners installment can be some-what escaped in a microgrid. Moreover, for the planned use of the partial capacity, a multi-objective optimal compensation model has proposed to optimize the comprehensive power quality evaluation index and minimize the engaged capacity of an MFGCI for power quality improvement. In [19], the work to adopt a Hybrid Petri nets (HPNs) to model and analyze a microgrid that comprises of renewable energy sources is presented. The HPNs are usually used to model and analyze different hybrid systems with discrete-event and continuous discrete-time performances. Furthermore, to analyze the system performance, a reachability graph for microgrid hybrid system model is generated. Investigating the post designs via many choices can give decision-makers many active methods and therefore permit them to pick the greatest one. In [20], a dynamic droop load sharing method based on the renewable energy generation capacity is discussed. A stability analysis on renewable energy generation units is also discussed to find out the practical and theoretical restrictions. Furthermore, the proposed approach recognizes the dc working zone of inverter based energy system as solar 
irradiance variations and the droop factors conditions for an effective load sharing based on renewable available power, although every unit rating is also considered. In [21], an improved dual droop scheme for two stage converters for conditioning powers from renewable energy sources and inverters for power directing to isolated grids is presented. To define the essential control activities, the dual droop scheme uses both generated power and dc voltage. The old droop controlled system has presumed that the sources can always provide power demanded by them. For renewable energy system, it is possible with energy storage system. Energy storage can be costly depending on its capacity, hence improved dual droop scheme is used for this condition. The droop line of converter can be lowered by drop in dc voltage and droop power facility may be decreased the voltage or frequency. The coordinated dispatch approaches of electric vehicles to smooth load variations and renewable energy of the microgrid whereas confirming the quality of logistics facilities is discussed in [22]. Besides, microgrid model is offered to enhance the routes of driving, fast charging time and charging/discharging plans of the electric vehicles. The main aim is to lower the total operation cost of the microgrid although filling the necessities of the logistics supply responsibilities. A scenario-based robust energy management scheme considering the worst case renewable energy power generation and load is developed in [23]. To increase the total exchange cost and decrease the social assistances cost at the same time, a robust model is formulated and the improbability of renewable energy generation and load is defined as an uncertain set formed by interval calculation. Furthermore, to permit the probable testing situations, a taguchi's orthogonal array testing technique is used. In [24], a control system for a mocrogrid renewable energy system is proposed. The dispatchable and renewable energy system based distributed generator are taken as the part of microgrids. A decentralized two-level procedure is used to cope up the problem while taking the irregular outputs of distributed generator, inexact load consumption and synchronized operating points of dependent schemes. The main aims are to keep the voltage stability and trustworthy power supply to users. Furthermore, mixed integer linear programming based new model for optimization of hybrid energy system in suburban microgrids with storage system in which manageable appliances demand response is reasonably considered in the optimization difficulty with reduced design loads is presented in [25]. Suitable stochastic models are chosen, hence model considered the renewable energy sources essential stochastic behavior and the uncertainty including electric load calculation. This investigates the load flexibility on the sizing of components for a residential microgrid in Okinawa. In [26]], the growth of an intelligent dynamic energy management scheme (I-DEMS) for a smart microgrid is presented. For growing the I-DEMS available, strengthening learning outline and an evolutionary adaptive dynamic programming is presented. The I-DEMS is an optimal or nearoptimal DEMS proficient of executing islanded microgrid and grid-connected operations. The renewable energy sources and storage systems are utilized maximum using the I-DEMS. The I-DEMS provides the control signals of the energy dispatch, whereas a progressive network calculates the forwarded control signals. A time scale adaptive dispatch technique to enhance the reliability and attain an economic dispatch of renewable energy power system is developed [27]. To evaluate the reliability level of predictions error, the confidence interval and coefficient are accepted. According to the prediction error confidence interval, the time scale for dispatch renewable energy power system on islands is modified. The accurate meteorological data based green power generation in Hong Kong, and get that different renewable energy sources show varied time-changing and location-reliant profiles is presented in [28]. The supportive framework takes microgrids self-concerned performances and includes their short du-ration operational costs and long duration investment costs over the forecasting horizon. A reasonable cost sharing technique based on Nash bargaining to incentivize supportive arrangement has been designed in such way that all microgrids will be benefiting from supporting scheduling. An active two layer model predictive control technique for controlling the microgrid hybrid energy systems is presented in [29]. Nonlinear mixed integer optimization problem based control technique is used to reduce the running cost and to enhance the robustness beside uncertainties causing from photovoltaic power and load demand. A new forecast algorithm is the weighting factors update provides the reduction in the forecast error. The microgrid operation through a stochastic linear two-stage model in ambiguity environment is optimized in [30]. This model is explained by mixed-integer linear programming and compared with a deterministic model through different three cases with demand response on a sample microgrid. The network limits are carefully considered in the first phase while the security limitations are controlled for every Situation in the second phase. A unified energy management system for renewable energy grid integrated arrangements with batterysuper capacitor hybrid storage can be found in [31]. Depending on the accessibility of the renewable energy power and variations in the load, this scheme dynamically alterations the modes of renewable energy grid integrated systems. Moreover, the proposed scheme permits the transfer of real power with auxiliary facilities such as reactive power care, power factor enhancement, and current harmonic extenuation at the point of common coupling. The electricity charge minimization problem which comprises of multiple users equipped with distributed resource based on renewable energy is considered in [32]. A dynamic assessing model for buying and selling of electricity from/to the grid and bidirectional electricity communications are proposed. To calculate the amount of electricity spent, purchased, and sold, the optimization problems is expressed for partial information, perfect information, and no information availability situations. Furthermore, two distributed algorithms are proposed for the partial information and noinformation cases by using Q-learning and Lyapunov optimization. Besides, a model for the problem of microgrid planning with financial and inexact physical information is presented in [33]. This investigated the financial feasibility of the microgrid arrangement and regulates the best generation combination of distributed energy resources for system. A robust optimization method is used for studying prediction errors in load, market values, and flexible renewable generation. The best planning results firm in key problem are used in the sub problem to study the optimality of the key solution by scheming the worst-case best process under indeterminate circumstances. In [34], the implementation of a novel repeated neural system for optimization as it is useful to the best operation of grid-connected microgrid system is presented. The suggested network regulates the finest amount of power for one week for solar, wind, and battery systems. Furthermore, the proposed system permits optimizing the power source, reducing the power taken from utility grid, and enhancing the power provided by renewable energy sources. In [35], a new reconfigurable microgrid design involving 
solar, wind, fuel cell, and micro hydro based renewable energy system is proposed. Temporary and extended power standby are given with battery storage and ultra-capacitor. A complex microgrid system sustainability and reliability is confirmed by the reconfigurable microgrid control and power network. This scheme is supported through the advisory layer involving an advisory controller that cares long term mocrogrid optimization operation. In [36], a rule-based method based on IEEE Std 1159-2009 to agreement with the assessment of voltage deviations is proposed. Moreover, a model of a data acquisition system and supervisory control with adaptive cleaning and filter bank is presented. The observing of voltage deviations can be proficiently achieved and applied in the microgrid scheme of Taiwan Institute of $\mathrm{Nu}$-clear Energy Research with the use of applied technique. In [37], a new bus-signaling technique to attain independent synchronized performance of arrangement according to state of charge situations is proposed. Furthermore, a secondary synchronized control is presented to return the voltage changes created by primary control level without moldering coordinated performance. In [38], a method to reduce the harmonics from the grid parameters of the point of common coupling for microgrid system is presented. The location of the harmonic mitigation unit is chosen to decrease the harmonic level of the current and voltage harmonics unrelatedly of the uses of the renewable energy sys-tem in the microgrid. Fast and effective algorithm has been employed for phase recognition irrespective of the existence of harmonics in the system. In [39], a new flow invariants-based method to microgrid supervision and it is more natural, highly accessible, and lees complex in comparison with existing agent-based, droop control, and model predictive controlbased methods are presented. These stated benefits are represented by using microgrid system for a model system based on military onward operating base camp.

In [40], a coordinated design of islanded ac microgrids based on smooth switching droop control is presented. Simple power control of each renewable energy sources and and energy storage systems unit can be got by using this approach with continuous modes variations. Also, decentralized power supervision can be got by performing frequency bussignaling.

A novel distributed real-time electricity allocation system to decrease the electricity charges of the residential users, to enhance the total social profit of the smart microgrid/grid system, and to rise the reliability and energy efficiency of the microgrid can be found in [41]. Moreover, a problem has been formulated as a non-cooperative game with mechanism design. Also, results are compared with a central optimal electricity consumption system and to the result obtained from natural arrangement structure. In [42], a coordinated control scheme of virtual power plant which comprises controllable loads and solar system to adaptably adjusted combined output power of the virtual power plant is presented. The working ways of controllable loads and output power of the solar system are organized by using mixed integer programming problem. Temporarily, active power control method, every solar sys-tem can run in a dispatch mode and calculate its available maximum power as a input to a mixed integer programming problem. A supervisory control method for process of a lonely hybrid microgrid, which comprises of a DC microgrid and an AC microgrid is presented in [43]. Bidirectional converter is used to couple the DC and AC microgrids and act as a rectifier or an inverter. Furthermore, the supervisory controller is dignified by a state machine method and 15 different working modes are taken.
In [44], a new system operation approach and the consistent energy organization technique for a small scale dc microgrid using hybrid energy storage based on renewable energy is proposed. The ultra-capacitor element uses as single volt-age source through grid connected or islanded mode and the microgrid is organized to be an expectable port for the grid. To send or absorb predefined power from/to the grid with connected mode and nil with islanding mode, for this reasons microgrid is effectively controlled. The energy managing way is devoted to showing the total power of the micro-grid successfully and the total power is detached into low and high frequency modules. Furthermore, in [45], a robust control method for decreasing the system frequency nonconformity produced by load variation and renewable energy sources in a microgrid system including the storage device is proposed. Robust control technique has been developed for reducing the frequency nonconformity, in spite of the existence of model uncertainties. The frequency deviation are compared with the reference system comprises of the conventional PID control and governor to cope with renewable sources and load variations. A structure using alternating direction method of multipliers and model predictive control to optimize and control a microgrid, which comprises of solar system, limitable load, electric vehicles charge stations, and a standing battery electric storage component is developed in [46]. To permits the microgrid to enthusiastically adjust to variation in the working environment, an algorithm is used within a structure. The location works as a small microgrid which contribute in the power grid wholesale market. In [47], an approach of expressing a multiobjective optimization and achieves a Pareto-optimal result which compares with the quantified valuation tasks and explaining as a single-objective optimization difficulty is presented. Furthermore, three controller's cases are shown and compared. The proposed controller can re-duce the unstable generation negative influences to below the level of the system load. In [48], a modest method to synergistic control of distributed energy sources in low voltage microgrids is presented. This method can use the full capacity of distributed energy sources during islanded and grid-connected operating modes. In order to reduce the voltage changes and distribution losses whereas completely using the renewable energy sources, the control tracks quasi-optimum action of the microgrid. Furthermore, quick adaptation to changes of the absorbed and generated power is confirmed in every operational condition. A novel technique to control the power generated from isolated and autonomous microgrid based on existing energy sources can be found in [49]. The technique does not want wired communication between the renewable energy sources nor tip loads to waste the extra power generated in the microgrid. Furthermore, the technique estimates the power that is generated by every source at every time for balancing of energy into the microgrid. In [50], a new structure for energy management based on idea of quality-of-service in electricity is presented. The control center of microgrid goal to lower the operation cost of microgrid and keep the outage possibility of quality usage by electricity scheduling among energy storage arrangements, renewable energy sources, and microgrid. The problem is defined and a Lyapunov optimization method is used to develop an adaptive electricity arrangement algorithm by presenting the quality-of-service in electricity virtual lines and storage of energy virtual lines. Moreover, in [51], a complete analyses for reconnection, islanding, and black start for different situations is presented. The standard IEEE 34 bus distribution feeder is chosen and managed as a microgrid by addition of load profiles and distributed generations. 
Supervisory power supervisions have been well-defined to manage the changes and to lower the changes on frequency and voltage.

\section{Overview of Economic Feasibility of Microgrid Hybrid Energy System}

The hybrid energy system comprises of the wind and the solar photovoltaic system can fulfill the power demand according to need in the grid-connected mode as well as island mode. This system reduces the cost of electricity for the consumers because this is a cost-effective system for the long term. Furthermore, carbon emission from thermal power plant also reduces because the units generated from hybrid energy system do not need to buy. Moreover, wind speed prediction model and the regression models for estimation of global solar radiation using different metrological parameters are need to be developed.

In [52], an idea and associated execution of the services desired by the users to empower the smart grid in a smart home is presented. Furthermore, an economic study to evaluate the energy cost formed by the small renewable energy sources based installations has been performed. In [53], an energy and backup co-optimization system based on fuzzy logic with concern of high penetration of renewable energy is proposed. Under the statement of a fixed indecision set of renewables, a two phase easy system is presented for dissipating energy in the first phase and examination of feasibility and strength of re-dispatches in the second phase. Fuzzy sets are presented into the optimization system to signify the satisfaction degree of flexible improbability sets. A procedure to examine the feasibility of green-house gas and non-greenhouse gas emission decrease in a decontrolled electricity market can be found in [54]. The planned model considers the consequence of non-greenhouse gas emission price restrictions in combination with standard greenhouse gas emission restrictions for the planning aspects of thermal generation companies. Then, pare-to solutions is assessed for many probable scheduling situations. Also, a sensitivity study of many environmental, technical, and economic features is presented to observe the effect of non-greenhouse gas attention and renewable energy technologies presence in scheduling. In [55], the good communications between an independent a thermal power plant and pumped-storage hydropower plant to improve the power generation and storage is discussed. A stochastic dynamic game is expressed to describe the competition and the instant market value is demonstrated as a Cournot duopoly game. Furthermore, in [56], an economic feasibility study for the replacement of power generators moved of diesel stations by photovoltaic generation is presented. The proposal is depended on a renewable energy with an opinion to a better environment is auguring-discussions and results to a hopeful future. In [57], an effective dynamic probabilistic reserve sizing method using a kernel-based nonparametric density assessment and clustering algorithm to get the temporary error distributions is proposed. Also, the feasibility and economic belongings of the better-quality model related to current values used in Germany has been exhibited. In [58], an easy robust energy and reserve dispatch model to implement economical and reliable processes, in which the functioning choices are distributed into dispatch and predispatch is proposed. A healthy feasibility constraint set is obligatory on pre-dispatch values, and the operation limitations can be recuperated by altering re-dispatch subsequently wind generation grasps. The system is increased to more common dispatch choice creating difficulties including uncertainties in the structure of modifiable robust optimization. In [59], the literature which proves the technical feasibility of the energetic contribution of wind power in working reserves is presented. In disparity, the contribution emphases on the financial value of scheduling wind power as backup ability. Consequently, wind power assets are combined in a unit assurance model simulating the power plants day-ahead scheduling for meeting the mandate for power and assets. In [60], an optimization method based on a Multi-Objective Genetic Algorithm which uses great chronological tenacity insolation data reserved at 10 seconds data amount as a substitute of hourly data amount is presented. The planned procedure uses a techno-economic method to know the system design improved using many criteria with cost, size, and obtainability. The outcome is the starting point scheme cost essential to meet the load necessities and can be used to monetize auxiliary facilities that the smart DC microgrid can offer to the utility such as voltage regulation. In [61], a dayahead unit commitment in coal-wind concentrated power arrangements is presented. The coal based generators do not give a good environment for adding flexible wind generation due to high starting cost and long starting time. The decreased efficiencies because of coal based generation side as stately in enlarged the fuel intake and emissions can significantly weaken the wind power assistances to the scheme if coal based generation and wind generation are not correctly coordinated. Also, unit commitment is considered using wind power inconsistency and ambiguity separately in many wind power dispatch modes. In [62], a new frequency reestablishment approach in photovoltaic connected power systems with decentralized dynamic state estimation method and photovoltaic power system as a possibility power source is proposed. The power output of photovoltaic panels is increased when an unexpected increase in load demand happens in order to recompense the real power capacity of the generator and in order to re-establish the frequency of a definite generator bus bar. An unscented Kalman filter- based decentralized dynamic approximation is used to know the frequency of a particular generator bus bar. The model of the power sources and power load, having random components based on the, power supply reliability and limitation situations for the equipment numbers are considered for forming many assessment indexes for improving the scheme performance is established in [63]. A multi-objective optimization algorithm is suggested for adjusting the arrangement of a standalone wind-solar-battery hybrid power system. In [64], a joint reliability model of voltage source converter-based high voltage direct current linked offshore wind farms with the duration and frequency technique is proposed. A two level many state wind firms model is established in view of variations in wind speed. The offered model is used to the Roy Billinton test system for appropriateness studies. In [65], a new neural fuzzy technique to predict the hourly wind speed. Initially, a neural arrangement is planned for the single-inputrule-modules attached fuzzy inference system for combining the advantages of both the fuzzy and neural network is presented. Furthermore, to attain the minimum training errors and minimum parameters, a parameter learning algorithm based on a least square method is offered for the system. The wind speed prediction method for short term based on forecast model, wind generation, error improvement, support vector machines, and the prediction processes is proposed in [66]. The two dissimilar machine learning methods to evaluate the prediction intervals of time-series forecasts are discussed in 
[67]. These methods are used for wind speed prediction for short-term from a actual data set of hourly wind speed forecasts for the area of Regina in Saskatchewan, Canada. The methods that can be applied to process interval-valued inputs with multilayer perceptron neural networks is also used [68]. The technique has been used on synthetic case study and on an actual case study, in which the records display a high shortterm changeability. A pattern-based method to predict the short-term wind speed can be found in [69]. Furthermore, a generalized principal component investigation to spontaneously notice the designs hidden in the old data of wind speed has been introduced. A prediction model based on probabilistic fuzzy system for wind speed prediction in short duration is proposed [70]. Also, the proposed prediction model can get both deterministic and stochastic uncertainties, and assurance a improved prediction in difficult stochastic environment. In [71], a novel method for forecasting wind speed and direction is presented. This technique is based on using a linear time-series-based model involving the foretold intermission to its equivalent one and two year historical data. The general experiment to calculate the magnitude of solar irradiance falling upon a photovoltaic solar field can be found in [72]. The main goal of the study is to change a model thus the design parameters are involved in single model that measure the solar irradiance on solar fields.

The study in [73] presents the environment approachable materials based on dye-sensitized solar cells based on perovskite solar cells for the spectral necessity with changing parameters at particular different sites. In [74], a new model to integrate the roof-top solar photovoltaic and wind power on the demand side and supply side respectively is proposed. A demand response aggregator is presented to cope with uncertainties and permitted the participate in reserve markets. Moreover, a novel model is established considering both clients' choices to decrease and increase load by the aggregator.

In [75], the united influence of temporal averaging, plane translation mechanisms and component deconstruction on uncertainty is analyzed. A novel technique to reallocate hourly averaged data is suggested. This clearness index redistribution technique is based on the numerical rearrangement of clearness index standards and mostly modifies the bias mistake presented by sequential averaging. This method better the root mean square error of the extracted beam section on average from 14.38 to $2.51 \%$ and for the diffuse section from 15.08 to $0.79 \%$. The enhancement in the global in-plane irradiation accuracy was extra reasonable with a decrease in root mean square error of global in-plane irradiation from 3.73 to $1.31 \%$.

In [76], a reserved overall energy cost minimization problem and divide the problem into two parts: the user association problem and optimal bandwidth allocation problem, both are opposite to each other for effective use of green energy is formulated. Furthermore, an optimal bandwidth allocation algorithm is used to reduce the power consumption of every base position under a particular user association scheme. A centralized and spread user association algorithm is proposed for the user association problem to catch optimal feasible solutions based on the optimal bandwidth allocation algorithm for the efficient use of the green energy storage for energy cost minimization. In [77], a technique to estimate the probability distribution function of photovoltaic systems generated power based on the higher order Markov chain (HMC) is presented. The solar system output power is influenced by solar irradiance and ambient temperature and both are used as key features to categories many operating situations of the solar system. An HMC is presented which is based on considered historical data of solar photovoltaic power in each operating point.The15-minutes forward probability distribution function of power output of solar system is expected through the Gaussian mixture method by merging numerous distribution functions and by using the factors defined based on restrictions of HMC-based model.

In [78], the delay vector variance analysis to identify the nonlinearity and disorder in the solar irradiance data from the Earth Radiation Budget Satellite from October 15, 1984 to October 15, 2003 is presented. In [79], a high-precision model of grid point value datasets based solar irradiance forecasting using rainfall, relative humidity, and three-level cloud covers parameterization in Hitachi, Japan is presented. The correlation coefficient $r$ of $0.94,0.91,0.91,0.89$, and 0.92 have been found using 21UTC forecast type in 2012 datasets for Hitachi, Japan.

The Met Office station data from 1980 to 2012 to describe the inter annual variability of incident solar irradiance across the UK and to assess four standard past irradiance products to define the best appropriate for use in UK solar industry for system design and site selection can be found in [80].In [81], a novel solar irradiance forecasting technique for the Markov switching model based isolated microgrids is presented. This technique uses nearby accessible data to forecast one-dayahead solar irradiance for energy resources planning in isolated microgrids. The new model takes past data of solar irradiance, Fourier basis developments and clear sky irradiance to make linear models for three regimes. In [82], the enhancement to the standard extended light source solar profile model based on a better parameterization of the circumsolar irradiance is presented. The proposed model reduce the errors and amends for a misrepresentation of circumsolar ratio in standard model. Also, a model extension is offered, including the spectral sharing changes in the essential solar and circumsolar areas.

In [83], discussed about the outcomes of the fifth spectral irradiance measurement inter comparison and the influence the outcomes have on the spread of spectral divergence controls in the outdoor characterization of reference solar cell and photovoltaic devices. Ten laboratories and marketable associates with their personal devices were involved in the comparison. Furthermore, defines the inter comparison movement, defines variable statistical investigation used on attained data, information on the outcomes, and analyzes the influence these outcomes would have on the main adjustment of a c-Si PV reference cell with normal sunlight. In [84], a combined optimal distribution procedure of energy storage and renewable distributed generation to get financial profits is presented. The proposed technique reduces costs of Distribution Company whereas promising the profits of renewable distributed generation owner.

A new energy transaction mechanism to address the inherent changeability of green power for grid-connected base stations is introduced in [85]. An infinite-horizon optimization problem is expressed to get the best downlink convey beam formers and to reduce the probable energy transaction cost. The feasibility of storage systems in enhancing the financial and technical performance of the housing renewable based energy hub is discussed in [86]. A novel method has been planned in which economic dispatch difficulty has been expressed for an energy hub. The planned method defines the optimal energy supply demand and storage system process to reduce the hub overall energy cost. In [87], the feasibility of photovoltaic-wind penetration into 
an present utility grid for the city of Ibrahimyya in Jordan is investigated. Two sizing approaches are offered and the thousands of repetitions have been done to obtain the global independent sizing solution and it is used for economic analysis. In [88], an R-C thermodynamic model of building that powerfully interlinked to the consumption of power of heating ventilation air-conditioning (HVAC) system is introduced. A building-aggregator-grid contract framework is proposed and formulated a robust model predictive control algorithm to increases the profit of aggregator and reduces the expense of every contributing building to optimally state power flexibility .In [89], a novel design of a hybrid stochastic-robust optimization and then it is used to analyze a safety constrained optimal power flow is presented. It is used to reduce the carbon emissions by capably accommodating renewable energy sources.

\section{Grid-Connected Hybrid System Dynamic Analysis}

The dynamic behavior of microgrid is affected due to constantly change in solar irradiance, wind speed etc., which causes dc bus voltage oscillation and, hence, affects in proper system operation. Hence, Different techniques have been used to improve the dynamic behavior of microgrid. In [90], a grid-connected photovoltaic system is presented, which is employed by using the neutral-point-clamped inverter. Furthermore, a current feed-forward control loop is employed to enhance the dynamic behavior of photovoltaic system, due to change in the solar irradiance. In [91], an organized parameter plan standard for the best choice of the current loop proportional resonant controller and the extra capacitor current feedback coefficient to improve the weighted average current control method is presented. The acceptable range of the scheme control parameters can be got under altered interruption circumstances to see the system performance conditions. In [92], a nine-level single-phase inverter topology appropriate for grid-connected renewable energy systems is presented. The proposed PWM technique for inverter uses the generation of 9L waveform without having the voltage sensor, thus dropping the difficulty of the overall control arrangement. In [93], a pulse width modulation controlled boost type single phase grid-connected photovoltaic inverter with narrow storage inductance current is proposed, thus this improves the dynamics response of the system. In [94], the usefulness of the active damping based on notch filter, seeing the senses of the resonant frequency is explored. The dynamic performance of the complete gridconnected inverter system with either inverter current feedback or grid current feedback has been improved. A fuzzylogic controller based speed controller for induction motor drives indirect field-oriented control connected with a fourswitch three-phase inverter can be found in [95]. The fuzzylogic controller based control method improves the dynamic responses and reduces calculation burden. In [96], the theoretical calculation of total harmonic distortion of the pulse width modulation a single-phase inverter current is done. Besides, an asymptotic time-domain procedure for the assessment of a single-phase PWM inverter current excellence has been suggested.

A new adaptive sliding-mode and robust control for gridconnected photovoltaic system based on cascaded two-level inverter is proposed in [97]. The design of the control scheme is established to give reactive power and active power with inconstant solar irradiance. In [98], a better three-phase current controller with healthiness beside the noise in the response path is introduced. A better acquisition method is used to reduce the important spectral content in the area of low-order harmonics, which eliminates any noise from the feedback signals. In [99], a better grid-voltage feed forward method with improved feed forward accuracy is proposed using the open-loop basic repetitive predictor and the sensibly planned conditioning circuit. Further, many improvements have been made to decrease the distortion of signal and recompense the delays. In [100], the growth of two control approaches with an adaptive control scheme and a fuzzy neural network control scheme for a boost inverter is investigated. Energy management system based on an adaptive neuro-fuzzy inference system of a grid-connected hybrid system is investigated in [101]. The results attained by adaptive neuro-fuzzy inference system -based inverter control and PI-based inverter control are fairly comparable, but the dynamic response of the adaptive neuro-fuzzy inference system controlled inverter offerings a better dynamic response in comparison with the PI controller. In [102], a modest fuzzy logic controlled inverter system to control of a grid-connected inverter circuit is presented which ensembles good for variable speed wind turbine driven permanent magnet synchronous generator process in a wide working range. The dynamic performances of this scheme are examined to show the usefulness of the control approach. In [103], the reactive power balancing problem and voltage stability problem in islanded electrical systems equipped with inverters is considered. A voltage feedback controller is suggested, permitting for the use of circuit-theoretic investigation methods to the closed-loop system. Furthermore, in [104], the regulation of frequency for an islanded mode microgrid with flexible renewables is addressed. The voltage and frequency regulation loops are synchronized by a model predictive control controller, and the manageable re-sources are consecutively dispatched. Furthermore, the dynamic model for assessing the state of charge of battery energy storage system under a rapid response is presented. In [105], an evaluation approach to measure the things of lacking protection structure on reliability indices in microgrid is proposed. With the suggested evaluation approach, the importance of the influences of the protection scheme on the operational reliability are established with a $400 \mathrm{~V}$ microgrid scheme. In [106], a non-linear model of microgrid with synchronverter controlled scheme is presented. The system state matrix Eigen values with the involvement is-sues are investigated to decide the main parameters which affects the stability. Bifurcation theory is used to define the unstable occurrence as the fluctuation of system parameters. The consequence of a resistive super- conducting fault current limiter connected to a microgrid with a dynamic load structure is analyzed in [107]. The resistive super- conducting fault current limiter can efficiently dull the fault current in microgrid by fast giving protection and improves the transient stability. In [108], the second ripple current reduction method with involving two band pass filters into the output voltage and feedback of current in the energy storage converter is proposed. The scheme successfully mitigates the ripple current and enhances the dynamic performance. In [109], the deduction technique for a voltage balancers series based on study of Buck/Boost style voltage balancer is proposed. After analysis, the interleaved Buck/Boost topology is used for authentication and the results shows the worthy dynamic characteristic of the average current control approach. In [110], a stochastic model to examine the transmission system dynamic coupling, the electricity value, and microgrid is proposed. This study 
focused on the effect of microgrids on the system transient response as well as on frequency variations. In [111], a novel method for power/current oscillations in dc microgrids is proposed. The efficient tuning of the voltage controlled distribution generation forward gain can increase the microgrid damping factor and improves the dynamic response of the complete system. In [112], a control method for microgrid with bidirectional converters analogized and virtual synchronous machine to improve the inertia of microgrid and to confine the voltage variation of $\mathrm{dc}$ bus is proposed. The study in [113] presents the complex microgrids and designed the sliding mode type advanced control approaches to control them. Furthermore, a suboptimal algorithm based decentralized second-order sliding mode control method is designed for every distribution generation units. In [114], a droop control scheme based detailed small-signal state-space model of a microgrid is established to overcome the problem of dynamic response with inverter and load dynamics and at that time joint with a reference frame to achieve the whole model.

\section{Intelligent Technique-Based Control of Microgrid Hybrid Energy System with Power Quality Enhancement Capabilities}

The hybrid energy system consists of a dc/dc converter with the 3-phase inverter circuit, where one controls the wind and solar power, while another is used for grid integration. For controlling the output voltages and currents of 3-phase inverter circuit, different control schemes are used i.e. PI, PD, PID, fuzzy, predictive control etc. Therefore, these controllers are used to enhancing the power quality, minimize the disturbance in the input voltage of inverter circuit, and improves the reliability.

In [115], a controller based on recurrent fuzzy cerebellar model articulation neural system is proposed to control the grid- connected photovoltaic system reactive and active power during the faults of the grid. To fulfil the low-voltage ride through necessities and confirm the safety limit of injected current, the reactive and active power instructions are known by using the low-voltage ride through current profile grid necessities and the limit of the inverter current. In [116], execution of space vector pulse width modulation (SVPWM) based on random forest regression is presented for an inverter to enhance the drive performance. Furthermore, SVPWM arrangements based on artificial neural network and an adaptive neuro-fuzzy inference system are used and compared with the proposed scheme. In [117], an effective current control scheme for grid-connected inverters is proposed to discard the dc offsets influence and scaling grid voltage measurement faults on the performance of the grid current. The current controller scheme is settled with three vector PI controllers plus a proportional integral. The grid currents are effectively controlled to be sinusoidal, balanced, and low harmonics. A novel control system for synchronization of a photovoltaic system to the grid using self-tuning perception can be found in [118]. The synchronization method is used to eliminate the harmonics in the load current, to get the maximum power and supply it into the grid. In [119], a fuzzy logic controller to remove present unified power flow controller's problems and to offer the dynamic power control through transmission lines is proposed. While many research have been concentrating on emerging unified power flow controllers control approaches for control of power through simulation hence a laboratory prototype has been established with two 6-pulse converters. In [120], a new nested-loop control approach to control the grid-forming inverter system having loads and an LC filter is proposed. The technique does not need a specific model for the inverter and can well treat with uncertainties and resonance of LC filter without having any damping mechanisms. In [121], the sliding-mode current controller based on invariable frequency pulse width modulation is designed and applied to a grid connected inverter. The method is based on a fixed switching frequency operation and Gao's reaching rule that permits chattering compensation. Furthermore, the split capacitors dc-link voltages are controlled with a basic proportional-integral controller. In [122], a state feedback control law with a disturbance viewer is proposed to improve the disturbance denial ability of a grid-connected photovoltaic inverter. The resultant control law has a proportional-integral (PI)/nearly PI-derivative-like arrangement, which is suitable for realtime application. In [123], an $\mathrm{H} \infty$ robust control of wind turbine inverters using an inductor-capacitor-inductor filter is proposed. The controller dynamics are planned for particular harmonic filtering in an offshore transmission system with parameters variations. Parameter uncertainty in the system creates due to the number of wind turbine connected and the grid. In [124], a vector control method based on recurrent neural network is proposed for an inverter with an LCL filter. The neural system is expert based on adaptive dynamic encoding principle, and the training objective is to good optimal control. Furthermore, the vector control method is compared with the old control methods like conventional PIbased vector control scheme and the PR-based control method for single-phase inverters. The study in [125] introduces a smart extraction of best power by using fuzzy logic control system from a hybrid energy system consist of a wind energy and a small concentration photovoltaic system. A fuzzy logic is implemented to extract maximum power from the photovoltaic system under fluctuating solar irradiance. Besides, Power extracted from wind system is implemented as a fuzzy function of the dc voltage error, rate of change and the direct axis current error of the inverter.

In [126], a new controller in a fixed reference frame for synchronous generator of grid connected wind system is proposed. The wind energy system used a Back-To-Back converter scheme with inverter and a phase- locked loop to know the voltage node fundamental frequency and its phase that is coupled to the scheme generation. Furthermore, the adaptive PI controllers are used to control the frequency, current, and DC-link voltage. In [127], the modelling and real analysis of a precise fuzzy logic controller for control of a grid-connected photo voltaic inverter is presented. The control algorithm was executed in actual time by DSP controller board DS1104. Al-so, the inverter is capable of transfer the accessible extra photovoltaic power to the utility grid. In [128], the transient stability improvement of a wind farm using flywheel energy storage scheme based on doublyfed induction ma-chine is investigated. A cascaded adaptive neuro-fuzzy controller is presented to control the frequency converter and to improve the transient stability of the gridconnected wind farm. In [129], a fuzzy-PI controlled grid interactive inverter is implemented and the PI controller gains are determined and adjusted by the fuzzy logic controller according to need of the system. Finally, an adaptive PI controller is got which can accept the changes because of changed operation conditions, disturbances in grid and usual things with fast transient response. In [130], an intelligent proportional-integral based fuzzy logic scheme for immediate reduction in system frequency deviation and power variations 
is implemented which essential for good operation of the load-frequency control scheme is relating to the wind power connected power systems. In [131], a fuzzy PI and a usual PI controllers for controlling the battery charging is described which is connected to a photovoltaic system. Grid-connected inverter controls the power transferred into the grid and controls the DC-link voltage. Also, the DC-link voltage is regulated by a fuzzy PI or classical PI controllers to know the amount of current and, thus, power injected or absorbed into the grid. In [132], the photovoltaic system based on single stage single phase current source inverter for grid connection is proposed. The system uses the trans-former free singlestage conversion for interfacing the photovoltaic system to the grid and tracing the maximum power point. A proportionalresonant controller is connected to control the grid injected current. To enhance the power quality of the system, a doubletuned parallel resonant circuit is used.

In [133], a new adaptive neuro-fuzzy control method for the renewable energy system interfacing inverter is presented. The joint capability of neuro-fuzzy controller in management the uncertainties is showed to be beneficial while controlling the inverter under changing operating conditions. The study in [134] addresses a novel intelligent method using the fuzzy logic and the particle swarm optimization methods for best tuning of the present proportional-integral based frequency controllers in the ac microgrid systems. The study in [135] proposes a novel scheme consist of two Fuzzy logic systems to make the maximum power-point-tracking algorithms. The first fuzzy logic system is based on a improved hill climb search algorithm to settle the power set-point. The second fuzzy logic system is an adaptive proportional integral controller that uses a flexible structure tuning algorithm to know the power set-point.

In [136], the different applications of huge photovoltaic farms equipped with a fuzzy gain scheduling of proportionalintegral-derivative controller for transient balance of a power system is proposed. The proposed controller is applied to control the photovoltaic inverter, hence the power output of photovoltaic system can be controlled to calm the transient power swing. In [137], the problem of voltage regulation in low-voltage power supply systems integrated with the solar photovoltaic system is discussed. Also, the new proportionalintegral-derivative control system has been proposed to interface the inverter based on intelligent adaptive neurofuzzy inference system for controlling the three-phase gridconnected solar PV system voltage under changing operating conditions. In [138], an intelligent control of wind power smoothing using recurrent fuzzy neural network is proposed. The battery energy storage system is comprised of a bidirectional DC/DC converter and 3-level inverter. Also, the difference of the smoothed power and actual wind power is provided by the battery energy storage system. In [139], the fuzzy logic controller which is combined to systematically regulate the dwell time provision for all the switching states of the three-phase three- level inverter is presented. Based on this method, neutral-point voltage deviation degree is handled, and at the same time, the most suitable dwell time which contributes to decrease in neutral-point voltage deviation is identified. In [140], a flexible grid link method of a inverter based on a direct power control scheme under variable grid situations is proposed. By examine the power terms, three algorithms based on the different control limits are used to make a cooperation among the active power ripples, the current negative sequence, and the reactive power ripples. Also, the proportional-integral-resonant type controller is used to track the sudden power errors. The study in [141] presents a finite-control-set model predictive control for a three-phase inverter under variable load condition. The control method can eliminates the inductor current doubleline frequency ripple with a modest and in effect approach.

In [142], a new method to decentralized control of multiple distributed generators is proposed. This method is based on a grouping of a voltage controller by using model predictive control and a current controller by using a discretetime sliding-mode controller to limit the inverter currents under overload situations. In [143], a novel method to solve the optimization problem in implicit model-predictive control that has a computational difficulty about five times less than that of explicit model-predictive control is proposed. The implicit model-predictive control needs a large number of calculations, whereas explicit model-predictive control cannot directly combine real-time variations in model factors, although still being computationally expensive than other control methods like dead beat control, hysteresis etc. In [144], an active power filter-integrated single-phase quasi Zsource inverter and its model predictive direct power control are proposed to totally eliminate the $2 \omega$ pulsating power from the dc side of the inverter. The study in [145] explores the novel power conversion scheme for wind turbines rated at the megawatt level. To control the grid-connected inverter and boost converter, a simple method based on a two-step model predictive approach is offered. In [146], a dual-active bridge converter with a floating inverter is presented. A set of discharging and charging switching orders have been recognized to permit the control of the fluctuating capacitor bridge voltage. A model predictive control method is implemented to control the current of the load and voltage of the floating capacitor. In [147], the use of model predictive control to a multi-megawatt range variable speed drive system is presented. The drive scheme consist of a synchronous machine fed by a rectifier and a inverter. The control aim is to adjust the dc-link current and to confirm the machine speed follows a specified reference. In [148], the distributed model predictive control of a wind farm connected with the short and fast-term energy storage scheme for best active power adjustment using the fast gradient method is presented. In [149] a model-predictive control of four-level grid-connected diode-clamped inverter in high power wind energy system is presented. By using the discrete-time model of the inverter, inductive filter, dc-link, and grid, the future performance of the dc-link voltages and grid currents is predicted for the likely switching states. The study is [150] presents a model predictive control system for quasi-Z-source inverter. The suggested topology has a wide range of voltage gain which is appropriate for use in renewable energy systems, where the renewable energy sources output fluctuates extensively with operating situations such as temperature, wind speed, and solar irradiation. In [151], a predictive torque control system for the four-switch three-phase inverter-fed induction motor with the offset suppression of the dc-link voltage is proposed. The three-phase balanced currents are got and the capacitor voltage offset is suppressed in this scheme.

The study in [152] presents a model predictive control scheme for a three-phase quasi-Z-source inverter that completes the essential necessities without addition the layers of control loops. The controller provides a discrete time model of quasi-Z-source inverter for predicting the future performance of the variables for every switching state with a set of multiobjective control variables entirely in one cost function. In [153], a common-mode voltages reduced modelpredictive control is proposed to eliminate the common-mode voltages peak value by choosing best space vectors for 
equally current-source inverter and current-source rectifier and at the same time. In [154], a direct model predictive current control scheme is presented for quasi-Z-source inverters. All sides of the inverter are controlled at the same time based on current of inductor and voltage of capacitor on the dc and ac sides. In [155], the implementation of nonlinear proportional- integral predictive controller for a gridconnected inverter is presented which is used in photovoltaic systems. A predictable cascade arrangement is chosen to design the controller and the outer loop and inner loop is used to control the dc-link voltage and adjusting the reactive and active powers supplied to the grid respectively. In [156], a novel control scheme for a grid-tied voltage-source inverter is presented using model predictive control structure with continuous transfer characteristics. This strategy can decoupled power control in grid-tied mode, control the load voltage in islanded mode and continuous transition between operation modes through suggested synchronization and phase adjustment algorithm. In [157], a better modelpredictive-flux-control is developed which is based on a three-phase flux-reversal drives fed by four-switch voltagesource- inverter with less number of switches and lesser costs. The voltage deviations across the capacitors are suppressed by using an analytical expression of the voltages of the DClink capacitor to disclose the natural relationship between phase currents and capacitor voltages. In [158], a novel model predictive control algorithm is proposed to lessen the number of calculations for multi-level cascaded H-bridge inverters and there are only three voltage vectors are used for calculation irrespective of the level of cascaded H-bridge inverters. In [159], a decoupled reactive and active power control method are presented for a grid-connected singlephase inverter by using model predictive control scheme. The controller reduces the switching state changes number essential to control the current whereas at the same time obliging the harmonics distortions and caring the inverter from overcurrent situation. In [160], the two-vector utilization based three model predictive current control techniques is proposed and then compared the voltage source inverters to control the currents of load and attain a less ripple and error. In [161], the model predictive current control is proposed to reduce the circulating current, control the voltage of neutralpoint as well as regulate the currents with rapid transient response. In [162], an appropriate large prediction horizon model predictive control design for cascaded H-bridge inverters is proposed. The model predictive control is designed to take in the full information of steady-state system in terms of output voltage and output current references.

The study in [163] proposes the hysteresis model predictive control system to control a high-power grid-tied voltage source inverter with the filter. Furthermore, the modeling error effects on stability of the system and normal switching frequency are investigated. The study in [164] presents the design the wind energy system based on dc grid in a poultry farm. A model predictive control algorithm which offers the well transient response with variation in the operating conditions is suggested for the control of the inverters. In [165], a model predictive-based maximum power extraction technique is presented for a grid-connected Zsource inverter based a photovoltaic system. In [166], the design of a finite-control-set model predictive control method is presented which deals with the difficult nature of the packed U cells. Besides, digital simulation for a 7-level gridtied single-phase packed U cells inverter was done. In [167], a finite control set-model predictive control scheme is proposed for quasi Z-source inverter. The scheme keeps the digital processor computational power at the time of implementation of the complete controlling scheme. In [168], power balancing mechanism based an effective model predictive control method is proposed for pulse width modulation rectifier-inverter. The fluctuation in dc-link voltage at the dynamic step response has been reduced successfully. In [169], a novel model prediction control based common-mode voltage reduction approach is proposed for inverter and it is also useful for permanent magnet synchronous generator based control scheme. In [170], a model predictive control scheme to decrease the commonmode voltage of three-phase inverters is proposed. Only nonzero voltage vectors are used to decrease the common-mode voltage and to regulate the load currents. In [171], the lyapunov stability ideas for finite control set model predictive control is proposed. This controller design permits one to describe the performance of the controlled converter, while giving enough circumstances for local stability of a power converters. In [172], an effective dc-link voltage fast control method based on energy balance is presented to decrease the variation in the dc-link voltage for a rectifier-inverter system. The study in [173] presents a better deadbeat predictive current controller for grid-connected inverters that reports the matters related to execution delays. The control method based on a system that involves the state feedback, delays, and a prediction observer to achieve a good ripple-free deadbeat response. In [174], a model predictive method to control the grid-tied high-power inverter is proposed. To know the future performance of dc link capacitor voltages and grid power values, a discrete-time model of the inverter is established.

\section{Efficient DC/DC Converters for DC MIcrogrids}

Microgrids are useful to reduce the computational and communication burdens caused by increased number of renewable energy sources and storage system. A DC/DC converter is used to add the wind and solar sources to the DC microgrid. The DC voltage generated by hybrid energy system is regulated by using DC/DC Converter. There are various types of converters available to integrate the wind and solar system to the Microgrid. As voltage and frequency vary along with the wind speed changes in wind energy system as well as output voltage of solar photovoltaic system varies along with the solar irradiance changes, therefore a proper control action is desired to obtain the constant voltage at the output of the systems.

In [175], a new multi-input DC/DC converter based on single-ended primary-inductor converter is presented. The converter has a two directional input port and connected with the energy storage system and a number of one directional input ports. This converter can be used to integrate the renewable energy sources. In [176], a novel three-port dc/dc converter is presented for hybrid applications. The structure consist of a basic buck-boost and a boost converter. The suggested converter voltage gain is more than the basic boost converter. The study in [177] proposes a novel multi input three-level converter for alternative energy sources which adopts the high dc link voltage. Renewable energy sources are added to the three-level $\mathrm{dc} / \mathrm{dc}$ converter previously the isolation step, causing the decreased part-count, defining the level of dc link voltage and permit-ting the flexibility in transformer design. In [178], the idea of the power efficiency optimization of inter-leaved step-down DC/DC converter with segmented power phases is presented. Furthermore, usage of the segmented switches allows for maintaining all 
the power phases active during low load condition. In [179], a combined solution of photovoltaic isolated dc/dc three-port converter is proposed to decrease the cost and enhance the power density of the sys-tem. The control approaches for the single module to get the maximum power, charge control of the battery, and main bus regulation have been proposed.

The study in [180] proposes a scheme by using a grouping of a charging switch and a series-connected double-input dc/dc converter. Furthermore, charge and dis-charge feature of the bootstrap mode is examined and the charging loss is evaluated.

In [181], the all operating modes of the boost converter and total probable cases are presented which help in the voltage balancing are explained to balance the capacitor voltages in a three-level inverter. In [182], a robust sliding-mode controller based on pulse width modulation is presented to control the boost converter feeding the constant power load in a microgrid situation. A non-linear surface is suggested to confirm the constant power deliver to the load. In [183], a novel multi-input DC/DC converter is proposed which has high-voltage transfer gain. The converter comprises of the conventional buck-boost and boost converters in all the stages except the last one and the last stage is the basic boost converter. In [184], a one-cycle control for two-input buck converter is proposed to remove the interfaces of the control loops easy the design of the controllers. In hybrid energy systems, the application of multi input converter is advantageous because of easy circuit and less cost in comparison with single input converters.

The study in [185] presents a novel multiple output DC/DC converter scheme that has step-down and step-up conversion abilities. In this scheme, many output voltages can be generated and then can be used in different applications. In [186], a quantitative technique to calculate the microgrids accessibility by recognizing and determining the less cut sets existence probability for different microgrid designs and converter topologies is presented. Besides, conventional scheme with single-input converters and other arrangements with multiple-input converters are considered. In [187], a different control approach based on the precise characteristics of islanded microgrids is proposed. Many distribution generation are coupled to the microgrid with a powerelectronic inverter with dc link. In [188], the control method and power management strategy is presented for combined three-port converter which is used to interface solar input port, bi-directional battery port, and an output port. In [189], a multiple-input converter by disintegrating the converters into cells, output filters, and a set of basic rules is proposed. Hybrid energy systems supply power to the grid or load from many alternative energy sources. For this system, the use of a multiple-input converter has the benefit of easy circuit structure and less cost compared with use of many singleinput converters. The study in [190] proposes the single-input dc-dc converter scheme that is used to build the multipleinput converter type. The study is based on many assumptions, limitations, and circumstances.

\section{Future Trends}

The main challenges ahead in perfecting the performances of grid-connected hybrid energy system are given below.

1) Proper Conversation Between renewable energy sources and control system handling Communities: Power engineering has been studied in the renewable energy sources area nowadays than in the non-renewable energy sources area. A Proper conversation between renewable energy sources and control system handling Communities is supposed to be done. A discussion between these two communities can improve the system performance. An example effort is combined panels at the IEEE Power and Energy Society General Meeting.

2) Efficiency Analysis: Performing efficiency analysis assistances assess the safe design of the system. This kind of analysis is more useful in renewable energy sources area, but it is main to apply the results to power system applications. Different authors present necessary and sufficient efficiency conditions for renewable energy sources based microgrid system. However, different power quality techniques also improve the efficiency of the system as well as system performance.

3) Output voltage of Renewable energy sources Analysis: There is for all time need of controlling the output voltage of different renewable energy sources. This kind of analysis is more useful in control area, but it helps the different loads to be operate safely. If the output voltage is varying according to different parameters then fluctuations may occurs which is very dangerous to the connected loads.

4) Cyber security Concerns: One of the important consideration to protect system against cyberattacks is to secure the system. The communication network is always weak to cyber-attacks by threads. Then, attention is obligatory for developing renewable energy sources based microgrid systems.

5) Implementing different techniques which comprise storage system: The different techniques for controlling the entire system should be implemented but there is a need of storage system for storing excess energy flow and when needed this storage system can provide the energy to the microgrid system. The storage system should also be controlled using intelligent techniques.

6) Utility Revision: The Utilities and other investors should be considered in the power area. Extensive real-time simulation system as well as pilot project system useful for dazed this barrier for actual implementation.

7) High voltage system: There is a need of high voltage microgrid system because there are many customers such as residential, Industrial, commercial etc. hence high voltage is needed for costumers. So, the voltage profile can be enhance using different controller based on power electronics circuitry for controlling the voltage.

\section{Conclusion}

Microgrid perception is presently growing across the world, leading to many opportunities and challenges. There are several microgrids which are connected to the central grid and may be disconnected and it operates in islanded mode and reduces central grid instability issues. Microgrids are generally installed by the community to which it has to serve and this is usually a low voltage ac grid. By integrating several distributed power generators together, the protection and control of a microgrid become a challenge. Microgrid has 
an important feature of providing several. This paper efforted to give a review of the state of the ability in research on microgrid hybrid energy systems, therefore leading the way for researchers and inventers in ahead insight into this essential topic nowadays and know a variety of hybrid energy systems related issues under analysis by the research community. The review included an introduction to sustainable microgrid primarily powered by renewable energy, an overview of economic feasibility of microgrid hybrid energy system, dynamic analysis of the system in enhancing grid performance, intelligent technique-based control with power quality enhancement capabilities, and the overview of the effective DC/DC converters for DC Microgrids. Finally, the challenges ahead in perfecting the performances of hybrid energy system are identified.

This is an Open Access article distributed under the terms of the Creative Commons Attribution License

\section{References}

[1] Z. Zeng and W. Shao, "Reconnection of micro-grid from islanded mode to grid-connected mode used sliding Goertzel transform based filter," IET Renew Power Gener, vol. 11, no. 7, pp. 10411048, 2017.

[2] K. Sun, X. Wang, Y. W. Li, F. Nejabatkhah, Y. Mei, and X. Lu, "Parallel Operation of Bidirectional Interfacing Converters in a Hybrid AC/DC Microgrid Under Unbalanced Grid Voltage Conditions," IEEE Trans Power Electron, vol. 32, no. 3, pp. 18721884, 2017.

[3] N. Korada and M. K. Mishra, "Grid Adaptive Power Management Strategy for an Integrated Microgrid With Hybrid Energy Storage," IEEE Trans Ind Electron, vol. 64, no. 4, pp. 2884-2892, 2017.

[4] C. Zhang, Y. Xu, Z. Y. Dong, and J. Ma, "Robust Operation of Microgrids via Two-Stage Coordinated Energy Storage and Direct Load Control," IEEE Trans Power Syst, vol. 32, no. 4, pp. 2858 2868, 2017.

[5] S. Kotra and M. K. Mishra, "A supervisory power management system for a hybrid microgrid with HESS," IEEE Trans Ind Electron, vol. 64, no. 5, pp. 3640-3649, 2017.

[6] V. Mohan, R. Suresh, J. G. Singh, W. Ongsakul, and N. Madhu, "Microgrid Energy Management Combining Sensitivities, Interval and Probabilistic Uncertainties of Renewable Generation and Loads," IEEE J Emerg Sel Top Circuits Syst, vol. 7, no. 2, pp. 262 $270,2017$.

[7] A. Iovine, S. B. Siad, G. Damm, E. De Santis, and M. D. Di Benedetto, "Nonlinear Control of a DC MicroGrid for the Integration of Photovoltaic Panels," IEEE Trans Autom Sci Eng, vol. 14, no. 2, pp. 524-535, 2017.

[8] K. Kant, C. Jain, and B. Singh, "A Hybrid Diesel-Wind-PV based Energy Generation System with Brushless Generators," IEEE Trans Ind Informatics, vol. 3203, no. c, pp. 1-1, 2017.

[9] C. Yuan, M. Illindala, and A. Khalsa, "Co-Optimization Scheme for Distributed Energy Resource Planning in Community Microgrids," IEEE Trans Sustain Energy, vol. 8, no. 4, pp. 1-1, 2017.

[10] S. Singh, V. Kumar, and D. Fulwani, "Mitigation of destabilising effect of CPLs in island DC micro-grid using non-linear control," IET Power Electron, vol. 10, no. 3, pp. 387-397, 2017.

[11]B. Yan, P. B. Luh, G. Warner, and P. Zhang, "Operation and Design Optimization of Microgrids with Renewables," IEEE Trans Autom Sci Eng, vol. 14, no. 2, pp. 573-585, 2017.

[12] Y. Wang, M. Yu, and Y. Li, "Self-adaptive inertia control of DC microgrid based on fast predictive converter regulation," IET Renew Power Gener, vol. 11, no. 8, pp. 1295-1303, 2017.

[13] R. R. Karasani, V. B. Borghate, P. M. Meshram, H. M. Suryawanshi, and S. Sabyasachi, "A Three-Phase Hybrid Cascaded Modular Multilevel Inverter for Renewable Energy Environment," IEEE Trans Power Electron, vol. 32, no. 2, pp. 1070-1087, Feb. 2017.

[14] S. S. Thale and V. Agarwal, "Controller Area Network Assisted Grid Synchronization of a Microgrid With Renewable Energy Sources and Storage," IEEE Trans Smart Grid, vol. 7, no. 3, pp. 1442-1452, May 2016.

[15]A. Hintz, U. R. Prasanna, and K. Rajashekara, "Comparative Study of the Three-Phase Grid-Connected Inverter Sharing Unbalanced Three-Phase and/or Single-Phase systems," IEEE Trans Ind Appl, vol. 52, no. 6, pp. 5156-5164, 2016.

[16] Y. Liu, B. Guo, T. Zhang, R. Wang, and Y. Zhang, "Model predictive control-based operation management for a residential microgrid with considering forecast uncertainties and demand response strategies," IET Gener Transm Distrib, vol. 10, no. 10, pp. 2367-2378, 2016.

[17]F. Garcia-Torres, L. Valverde, and C. Bordons, "Optimal Load Sharing of Hydrogen-Based Microgrids with Hybrid Storage Using Model Predictive Control," IEEE Trans Ind Electron, vol. PP, no. 99, p. 1, 2016.

[18]Z. Zeng, H. Li, R. Zhao, S. Tang, and H. Yang, "Multi-objective control of multi-functional grid-connected inverter for renewable energy integration and power quality service," IET Power Electron, vol. 9, no. 4, pp. 761-770, 2016.

[19] X. Lu, M. Zhou, A. C. Ammari, and J. Ji, "Hybrid Petri nets for modeling and analysis of microgrid systems," IEEE/CAA J Autom Sin, vol. 3, no. 4, pp. 349-356, 2016.

[20] A. M. Egwebe, M. Fazeli, P. Igic, and P. M. Holland, "Implementation and Stability Study of Dynamic Droop in Islanded Microgrids," IEEE Trans Energy Convers, vol. 31, no. 3, pp. 821-832, 2016.

[21] H. Liu, Y. Yang, X. Wang, P. C. Loh, F. Blaabjerg, W. Wang, and D. G. Xu, "An Enhanced Dual Droop Control Scheme for Resilient Active Power Sharing among Paralleled Two-Stage Converters," IEEE Trans Power Electron, vol. 8993, no. c, pp. 1-1, 2016.

[22] H. Yang, H. Pan, F. Luo, J. Qiu, Y. Deng, M. Lai, and Z. Y. Dong, "Operational Planning of Electric Vehicles for Balancing Wind Power and Load Fluctuations in a Microgrid," IEEE Trans Sustain Energy, vol. 3029, no. c, pp. 1-1, 2016.

[23] Y. Xiang, J. Liu, and Y. Liu, "Robust Energy Management of Microgrid with Uncertain Renewable Generation and Load," IEEE Trans Smart Grid, vol. 7, no. 2, pp. 1034-1043, 2016.

[24]Z. Wang, B. Chen, J. Wang, and J. Kim, "Decentralized Energy Management System for Networked Microgrids in GridConnected and Islanded Modes," IEEE Trans Smart Grid, vol. 7, no. 2, pp. 1097-1105, 2016.

[25] R. Atia and N. Yamada, "Sizing and Analysis of Renewable Energy and Battery Systems in Residential Microgrids," IEEE Trans Smart Grid, vol. 7, no. 3, pp. 1204-1213, 2016.

[26] G. K. Venayagamoorthy, R. K. Sharma, P. K. Gautam, and A. Ahmadi, "Dynamic Energy Management System for a Smart Microgrid," IEEE Trans Neural Networks Learn Syst, vol. 27, no. 8, pp. 1643-1656, 2016.

[27] C. Li, X. Liu, Y. Cao, P. Zhang, H. Shi, L. Ren, and Y. Kuang, “A Time-Scale Adaptive Dispatch Method for Renewable Energy Power Supply Systems on Islands," IEEE Trans Smart Grid, vol. 7, no. 2, pp. 1069-1078, 2016.

[28]H. Wang and J. Huang, "Cooperative Planning of Renewable Generations for Interconnected Microgrids," IEEE Trans Smart Grid, vol. 7, no. 5, pp. 2486-2496, 2016.

[29] J. Sachs and O. Sawodny, "A Two-Stage Model Predictive Control Strategy for Economic Diesel-PV-Battery Island Microgrid Operation in Rural Areas," IEEE Trans Sustain Energy, vol. 7, no. 3, pp. 903-913, 2016.

[30] S. Talari, M.-R. Haghifam, and M. Yazdaninejad, "Stochastic-based scheduling of the microgrid operation including wind turbines, photovoltaic cells, energy storages and responsive loads," IET Gener Transm Distrib, vol. 9, no. 12, pp. 1498-1509, 2015.

[31] N. R. Tummuru, M. K. Mishra, and S. Srinivas, "Dynamic Energy Management of Renewable Grid Integrated Hybrid Energy Storage System," IEEE Trans Ind Electron, vol. 62, no. 12, pp. 7728-7737, 2015.

[32] Y. Liu, C. Yuen, N. Ul Hassan, S. Huang, R. Yu, and S. Xie, "Electricity Cost Minimization for a Microgrid with Distributed Energy Resource under Different Information Availability," IEEE Trans Ind Electron, vol. 62, no. 4, pp. 2571-2583, 2015.

[33]A. Khodaei, S. Bahramirad, and M. Shahidehpour, "Microgrid 
Planning Under Uncertainty," IEEE Trans Power Syst, vol. 30, no. 5, pp. 2417-2425, Sep. 2015.

[34]M. E. Gamez Urias, E. N. Sanchez, and L. J. Ricalde, "Electrical Microgrid Optimization via a New Recurrent Neural Network," IEEE Syst J, vol. 9, no. 3, pp. 945-953, Sep. 2015.

[35]S. S. Thale, R. G. Wandhare, and V. Agarwal, "A Novel Reconfigurable Microgrid Architecture With Renewable Energy Sources and Storage," IEEE Trans Ind Appl, vol. 51, no. 2, pp. 1805-1816, 2015.

[36]C. I. Chen and Y. C. Chen, "Intelligent Identification of Voltage Variation Events Based on IEEE Std 1159-2009 for SCADA of Distributed Energy System," IEEE Trans Ind Electron, vol. 62, no. 4, pp. 2604-2611, 2015.

[37] D. Wu, F. Tang, T. Dragicevic, J. M. Guerrero, and J. C. Vasquez, "Coordinated Control Based on Bus-Signaling and Virtual Inertia for DC Islanded Microgrids," IEEE Trans Smart Grid, vol. 6, no. 6, pp. 1-12, 2015.

[38]S. Anwar, A. Elrayyah, and Y. Sozer, "Efficient Single-Phase Harmonics Elimination Method for Microgrid Operations," IEEE Trans Ind Appl, vol. 51, no. 4, pp. 3394-3403, 2015.

[39] T. T. Gamage, Y. Liu, T. A. Nguyen, X. Qiu, B. M. McMillin, and M. L. Crow, "A novel flow invariants-based approach to microgrid management," IEEE Trans Smart Grid, vol. 6, no. 2, pp. 516-525, 2015.

[40] D. Wu, F. Tang, T. Dragicevic, J. C. Vasquez, and J. M. Guerrero, "A Control Architecture to Coordinate Renewable Energy Sources and Energy Storage Systems in Islanded Microgrids," IEEE Trans Smart Grid, vol. 6, no. 3, pp. 1156-1166, 2015.

[41] M. H. K. Tushar, C. Assi, and M. Maier, "Distributed Real-Time Electricity Allocation Mechanism for Large Residential Microgrid," IEEE Trans Smart Grid, vol. 6, no. 3, pp. 1353-1363, 2015.

[42]H. Xin, D. Gan, Y. Liu, and Z. Wang, "Control of virtual power plant in microgrids: a coordinated approach based on photovoltaic systems and controllable loads," IET Gener Transm Distrib, vol. 9, no. 10, pp. 921-928, 2015 .

[43]F. R. Salmasi and M. Hosseinzadeh, "Power management of an isolated hybrid AC/DC micro-grid with fuzzy control of battery banks," IET Renew Power Gener, vol. 9, no. 5, pp. 484-493, 2015.

[44] B. Liu, F. Zhuo, Y. Zhu, and H. Yi, "System Operation and Energy Management of a Renewable Energy-Based DC Micro-Grid for High Penetration Depth Application," IEEE Trans Smart Grid, vol. 6 , no. 3, pp. 1147-1155, May 2015.

[45] Y. Han, P. M. Young, A. Jain, and D. Zimmerle, "Robust control for microgrid frequency deviation reduction with attached storage system," IEEE Trans Smart Grid, vol. 6, no. 2, pp. 557-565, 2015.

[46]T. Wang, D. O'Neill, and H. Kamath, "Dynamic Control and Optimization of Distributed Energy Resources in a Microgrid," IEEE Trans Smart Grid, vol. 6, no. 6, pp. 2884-2894, 2015.

[47]M. Ross, C. Abbey, F. Bouffard, and G. Joos, "Multiobjective optimization dispatch for microgrids with a high penetration of renewable generation," IEEE Trans Sustain Energy, vol. 6, no. 4 pp. 1306-1314, 2015.

[48] T. Caldognetto, S. Buso, P. Tenti, and D. I. Brandao, "PowerBased Control of Low-Voltage Microgrids," IEEE J Emerg Sel Top Power Electron, vol. 3, no. 4, pp. 1056-1066, Dec. 2015.

[49] J. de Matos, F. e Silva, and L. Ribeiro, "Power Control in AC Isolated Microgrids with Renewable Energy Sources and Energy Storage Systems," IEEE Trans Ind Electron, vol. 62, no. 6, pp. 1-1, 2014.

[50] Y. Huang, S. Mao, and R. M. Nelms, "Adaptive electricity scheduling in microgrids," IEEE Trans Smart Grid, vol. 5, no. 1, pp. 270-281, 2014

[51] Q. Fu, A. Nasiri, V. Bhavaraju, A. Solanki, T. Abdallah, and D. C. $\mathrm{Yu}$, "Transition management of microgrids with high penetration of renewable energy," IEEE Trans Smart Grid, vol. 5, no. 2, pp. 539-549, 2014.

[52]G. A. Pagani and M. Aiello, "Generating Realistic Dynamic Prices and Services for the Smart Grid," IEEE Syst J, vol. 9, no. 1, pp. 191-198, Mar. 2015.

[53] C. Liu, A. Botterud, Z. Zhou, and P. Du, "Fuzzy Energy and Reserve Co-optimization With High Penetration of Renewable Energy," IEEE Trans Sustain Energy, vol. 8, no. 2, pp. 782-791, Apr. 2017.

[54] S. R. Konda, L. K. Panwar, B. K. Panigrahi, R. Kumar, and S. Member, "A Multiple Emission Constrained Approach for Selfscheduling of GENCO Under Renewable," CSEE J Power Energy Syst, vol. 3, no. 1, pp. 63-73, 2017.

[55] N. Forouzandehmehr, Z. Han, and R. Zheng, "Stochastic Dynamic Game between Hydropower Plant and Thermal Power Plant in
Smart Grid Networks," IEEE Syst J, vol. 10, no. 1, pp. 88-96, Mar. 2016.

[56] L. F. Ramos, C. Krüger, and F. A. Farret, "Economical Feasibility of Alternative Sources as Secondary Means for Electricity Generation in Brazilian Gas Stations," IEEE Lat Am Trans, vol. 14, no. 4, pp. 1717-1723, 2016.

[57] M. Bucksteeg, L. Niesen, and C. Weber, "Impacts of Dynamic Probabilistic Reserve Sizing Techniques on Reserve Requirements and System Costs," IEEE Trans Sustain Energy, vol. 7, no. 4, pp. 1408-1420, Oct. 2016.

[58] W. Wei, F. Liu, S. Mei, and Y. Hou, "Robust Energy and Reserve Dispatch Under Variable Renewable Generation," IEEE Trans Smart Grid, vol. 6, no. 1, pp. 369-380, Jan. 2015.

[59] K. De Vos and J. Driesen, "Active participation of wind power in operating reserves," IET Renew Power Gener, vol. 9, pp. 566-575, 2015.

[60] M. B. Shadmand and R. S. Balog, "Multi-Objective Optimization and Design of Photovoltaic-Wind Hybrid System for Community Smart DC Microgrid," IEEE Trans Smart Grid, vol. 5, no. 5, pp. 2635-2643, Sep. 2014.

[61] C. Wang, Z. Lu, and Y. Qiao, "A Consideration of the Wind Power Benefits in Day-Ahead Scheduling of Wind-Coal Intensive Power Systems," IEEE Trans Power Syst, vol. 28, no. 1, pp. 236-245, Feb. 2013.

[62] S. Yu, S. Member, L. Zhang, and S. Member, "A DSE-Based Power System Frequency Restoration Strategy for PV-Integrated Power Systems Considering Solar Irradiance Variations," IEEE Trans Ind Informatics, vol. 3203, no. c, pp. 2511-2518, 2017.

[63] G. Ma, G. Xu, Y. Chen, and R. Ju, "Multi-objective optimal configuration method for a standalone wind-solar-battery hybrid power system," IET Renew Power Gener, vol. 11, no. 1, pp. 194 202, 2017.

[64]Y. Guo, H. Gao, and Q. Wu, "A Combined Reliability Model of VSC-HVDC Connected Offshore Wind Farms Considering Wind Speed Correlation," IEEE Trans Sustain Energy, vol. 8, no. 4, pp. 1637-1646, Oct. 2017.

[65] C. Li, L. Wang, G. Zhang, H. Wang, and F. Shang, "Functional-type single-input-rule-modules connected neural fuzzy system for wind speed prediction," IEEE/CAA J Autom Sin, vol. 4, no. 4, pp. 751$762,2017$.

[66] M. Mao, J. Ling, L. Chang, N. D. Hatziargyriou, J. Zhang, and Y. Ding, "A Novel Short-Term Wind Speed Prediction Based on MFEC," IEEE J Emerg Sel Top Power Electron, vol. 4, no. 4, pp. 1206-1216, 2016.

[67] R. Ak, O. Fink, and E. Zio, "Two Machine Learning Approaches for Short-Term Wind Speed Time-Series Prediction," IEEE Trans Neural Networks Learn Syst, vol. PP, no. 99, p. 1, 2015.

[68]R. Ak, V. Vitelli, and E. Zio, "An Interval-Valued Neural Network Approach for Uncertainty Quantification in Short-Term Wind Speed Prediction," IEEE Trans Neural Networks Learn Syst, vol. 26, no. 11, pp. 2787-2800, Nov. 2015.

[69]Q. Hu, P. Su, D. Yu, and J. Liu, "Pattern-Based Wind Speed Prediction Based on Generalized Principal Component Analysis," Sustain Energy, IEEE Trans, vol. 5, no. 3, pp. 866-874, 2014.

[70] G. Zhang, H.-X. Li, and M. Gan, "Design a Wind Speed Prediction Model Using Probabilistic Fuzzy System," IEEE Trans Ind Informatics, vol. 8, no. 4, pp. 819-827, 2012.

[71] T. H. M. El-Fouly, E. F. El-Saadany, and M. M. A. Salama, "One Day Ahead Prediction of Wind Speed and Direction," IEEE Trans Energy Convers, vol. 23, no. 1, pp. 191-201, 2008.

[72] S. Y. Alsadi and Y. F. Nassar, "Estimation of Solar Irradiance on Solar Fields: An Analytical Approach and Experimental Results," IEEE Trans Sustain Energy, vol. 8, no. 4, pp. 1601-1608, Oct. 2017.

[73]E. F. Fernandez, F. A. Cruz, T. K. Mallick, and S. Sundaram, "Effect of Spectral Irradiance Variations on the Performance of Highly Efficient," IEEE J Photovoltaics, vol. 5, no. 4, pp. 1150-1157, 2015.

[74] N. Mahmoudi, M. Shafie-khah, T. K. Saha, and J. P. S. Catalão, "Customer-driven demand response model for facilitating roof-top PV and wind power integration," IET Renew Power Gener, vol. 11, no. 9, pp. 1200-1210, 2017.

[75] K. Gibson, I. R. Cole, B. Goss, T. R. Betts, and R. Gottschalg, "Compensation of temporal averaging bias in solar irradiance data," IET Renew Power Gener, vol. 11, pp. 1-7, 2017.

[76] B. Wang, Q. Kong, W. Liu, and L. T. Yang, "On Efficient Utilization of Green Energy in Heterogeneous Cellular Networks," IEEE Syst J, vol. 11, no. 2, pp. 846-857, Jun. 2017.

[77] M. J. Sanjari and H. B. Gooi, "Probabilistic Forecast of PV Power 
Generation Based on Higher Order Markov Chain," IEEE Trans Power Syst, vol. 32, no. 4, pp. 2942-2952, 2017.

[78] M. H. Khondekar, D. N. Ghosh, K. Ghosh, and A. K. Bhattacharjee, "Complexity in Solar Irradiance From the Earth Radiation Budget Satellite," IEEE Syst J, vol. 9, no. 2, pp. 487-494, 2015.

[79] A. S. B. M. Shah, H. Yokoyama, and N. Kakimoto, "HighPrecision Forecasting Model of Solar Irradiance Based on Grid Point Value Data Analysis for an Efficient Photovoltaic System," IEEE Trans Sustain Energy, vol. 6, no. 2, pp. 474-481, 2015.

[80]P. Burgess, M. Vahdati, and E. Essah, "Investigation of the accuracy of historical irradiance products and interannual variability of solar irradiance using met office ground data," IET Renew Power Gener, vol. 9, no. 5, pp. 405-411, 2015.

[81] A. Shakya, S. Michael, C. Saunders, D. Armstrong, P. Pandey, S. Chalise, and R. Tonkoski, "Using Markov Switching Model for solar irradiance forecasting in remote microgrids," ECCE 2016 IEEE Energy Convers Congr Expo Proc, vol. 8, no. 3, pp. 895905, 2017.

[82] I. R. Cole and R. Gottschalg, "Improved model for circumsolar irradiance calculation as an extended light source and spectral implications for high-concentration photovoltaic devices," IEEE $J$ Photovoltaics, vol. 6, no. 1, pp. 258-265, 2016.

[83] R. Galleano, W. Zaaiman, D. Alonso-Alvarez, A. Minuto, N. Ferretti, R. Fucci, M. Pravettoni, M. Halwachs, M. Friederichs, F. Plag, D. Friedrich, and E. Haverkamp, "Results of the Fifth International Spectroradiometer Comparison for Improved Solar Spectral Irradiance Measurements and Related Impact on Reference Solar Cell Calibration," IEEE J Photovoltaics, vol. 6 , no. 6, pp. 1587-1597, 2016.

[84] V. Kalkhambkar, R. Kumar, and R. Bhakar, "Joint optimal allocation methodology for renewable distributed generation and energy storage for economic benefits," IET Renew Power Gener, vol. 10, no. 9, pp. 1422-1429, 2016.

[85] X. Wang, Y. Zhang, T. Chen, and G. B. Giannakis, "Dynamic Energy Management for Smart-Grid-Powered Coordinated Multipoint Systems," IEEE J Sel Areas Commun, vol. 34, no. 5, pp. 1348-1359, May 2016.

[86] M. H. Barmayoon, M. Fotuhi-Firuzabad, A. Rajabi-Ghahnavieh, and M. Moeini-Aghtaie, "Energy storage in renewable-based residential energy hubs," IET Gener Transm Distrib, vol. 10, no. 13, pp. 3127-3134, 2016.

[87] H. M. Al-Masri and M. Ehsani, "Feasibility Investigation of a Hybrid On-Grid Wind Photovoltaic Retrofitting System," IEEE Trans Ind Appl, vol. 52, no. 3, pp. 1979-1988, 2016.

[88] W. Mai and C. Y. Chung, "Economic MPC of Aggregating Commercial Buildings for Providing Flexible Power Reserve," IEEE Trans Power Syst, vol. 30, no. 5, pp. 2685-2694, 2015.

[89] A. J. Lamadrid, D. L. Shawhan, C. E. Murillo-Sanchez, R. D. Zimmerman, Y. Zhu, D. J. Tylavsky, A. G. Kindle, and Z. Dar, "Stochastically optimized, carbon-reducing dispatch of storage, generation, and loads," IEEE Trans Power Syst, vol. 30, no. 2, pp. 1064-1075, 2015.

[90] L. B. G. Campanhol, S. A. O. Da Silva, A. A. De Oliveira, and V. D. Bacon, "Dynamic Performance Improvement of a Grid-Tied PV System Using a Feed-Forward Control Loop Acting on the NPC Inverter Currents," IEEE Trans Ind Electron, vol. 64, no. 3, pp. 2092-2101, 2017.

[91] Y. Han, Z. Li, P. Yang, C. Wang, L. Xu, and J. M. Guerrero, "Analysis and Design of Improved Weighted Average Current Control Strategy for LCL-Type Grid-Connected Inverters," IEEE Trans Energy Convers, vol. 32, no. 3, pp. 941-952, Sep. 2017.

[92] N. Sandeep and U. R. Yaragatti, "Design and Implementation of a Sensorless Multilevel Inverter with Reduced Part Count," IEEE Trans Power Electron, vol. 32, no. 9, pp. 6677-6683, 2017.

[93] D. Chen, Y. Qiu, Y. Chen, and Y. He, "Nonlinear PWM-controlled single-phase boost mode grid-connected photovoltaic inverter with limited storage inductance current," IEEE Trans Power Electron, vol. 32, no. 4, pp. 2717-2727, 2017.

[94] W. Yao, Y. Yang, X. Zhang, F. Blaabjerg, and P. C. Loh, "Design and Analysis of Robust Active Damping for LCL Filters Using Digital Notch Filters," IEEE Trans Power Electron, vol. 32, no. 3, pp. 2360-2375, 2017.

[95] M. S. Zaky and M. K. Metwaly, "A Performance Investigation of a Four-Switch Three-Phase Inverter-Fed im Drives at Low Speeds Using Fuzzy Logic and PI Controllers," IEEE Trans Power Electron, vol. 32, no. 5, pp. 3741-3753, 2017.

[96]B. Reznikov, M. Srndovic, Y. L. Familiant, G. Grandi, and A. Ruderman, "Simple Time Averaging Current Quality Evaluation of a Single-Phase Multilevel PWM Inverter," IEEE Trans Ind
Electron, vol. 63, no. 6, pp. 3605-3615, 2016.

[97] N. Kumar, T. K. Saha, and J. Dey, "Sliding-Mode Control of PWM Dual Inverter-Based Grid-Connected PV System: Modeling and Performance Analysis," IEEE J Emerg Sel Top Power Electron, vol. 4, no. 2, pp. 435-444, Jun. 2016

[98] S. N. Vukosavic, L. S. Peric, and E. Levi, "AC current controller with error-free feedback acquisition system," IEEE Trans Energy Convers, vol. 31, no. 1, pp. 381-391, 2016.

[99] Q. Yan, X. Wu, X. Yuan, and Y. Geng, "An Improved GridVoltage Feedforward Strategy for High-Power Three-Phase GridConnected Inverters Based on the Simplified Repetitive Predictor," IEEE Trans Power Electron, vol. 31, no. 5, pp. 3880 3897, May 2016.

[100] R.-J. Wai, M.-W. Chen, and Y.-K. Liu, "Design of adaptive control and fuzzy neural network control for single-stage boost inverter," IEEE Trans Ind Electron, vol. 62, no. 9, pp. 5434-5445, 2015.

[101] P. Garcia, C. A. Garcia, L. M. Fernandez, F. Llorens, and F. Jurado, "ANFIS-Based Control of a Grid-Connected Hybrid System Integrating Renewable Energies, Hydrogen and Batteries," IEEE Trans Ind Informatics, vol. 10, no. 2, pp. 1107-1117, May 2014.

[102] S. M. Muyeen and A. Al-Durra, "Modeling and control strategies of fuzzy logic controlled inverter system for grid interconnected variable speed wind generator," IEEE Syst $J$, vol. 7, no. 4, pp. 817-824, 2013.

[103] J. W. Simpson-Porco, F. Dorfler, and F. Bullo, "Voltage Stabilization in Microgrids via Quadratic Droop Control," IEEE Trans Automat Contr, vol. 62, no. 3, pp. 1239-1253, Mar. 2017.

[104] L. Liang, Y. Hou, and D. J. Hill, "Design guidelines for MPCbased frequency regulation for islanded microgrids with storage, voltage, and ramping constraints," IET Renew Power Gener, vol. 11, no. 8, pp. 1200-1210, Jun. 2017.

[105] X. Xu, T. Wang, L. Mu, and J. Mitra, "Predictive Analysis of Microgrid Reliability Using a Probabilistic Model of Protection System Operation," IEEE Trans Power Syst, vol. 32, no. 4, pp. 3176-3184, Jul. 2017.

[106] Z. Shuai, Y. Hu, Y. Peng, C. Tu, and Z. J. Shen, "Dynamic Stability Analysis of Synchronverter-Dominated Microgrid Based on Bifurcation Theory," IEEE Trans Ind Electron, vol. 64, no. 9, pp. 7467-7477, Sep. 2017.

[107] D. Choi, J. Yoo, D. Kim, S. H. Lee, and J. Park, “Analysis on Effect of SFCL Applied to an Isolated Microgrid With a Dynamic Load Model," IEEE Trans Appl Supercond, vol. 27, no. 4, pp. 14, Jun. 2017.

[108] L. Yang, Y. Chen, A. Luo, W. Wu, K. Huai, X. Zhou, L. Zhou, Q. $\mathrm{Xu}$, and J. M. Guerrero, "Second Ripple Current Suppression by Two Bandpass Filters and Current Sharing Method for Energy Storage Converters in DC Microgrid," IEEE J Emerg Sel Top Power Electron, vol. 5, no. 3, pp. 1031-1044, Sep. 2017.

[109] F. Wang, Z. Lei, X. Xu, and X. Shu, "Topology Deduction and Analysis of Voltage Balancers for DC Microgrid," IEEE J Emerg Sel Top Power Electron, vol. 5, no. 2, pp. 672-680, Jun. 2017.

[110] P. Ferraro, E. Crisostomi, M. Raugi, and F. Milano, "Analysis of the Impact of Microgrid Penetration on Power System Dynamics," IEEE Trans Power Syst, vol. 32, no. 5, pp. 4101-4109, Sep. 2017.

[111] N. Rashidirad, M. Hamzeh, K. Sheshyekani, and E. Afjei, “An Effective Method for Low-Frequency Oscillations Damping in MultiBus DC Microgrids," IEEE J Emerg Sel Top Circuits Syst, vol. 7, no. 3, pp. 403-412, Sep. 2017.

[112] W. Wu, Y. Chen, A. Luo, L. Zhou, X. Zhou, L. Yang, Y. Dong, and J. M. Guerrero, "A Virtual Inertia Control Strategy for DC Microgrids Analogized With Virtual Synchronous Machines," IEEE Trans Ind Electron, vol. 64, no. 7, pp. 6005-6016, Jul. 2017.

[113] M. Cucuzzella, G. P. Incremona, and A. Ferrara, "Decentralized Sliding Mode Control of Islanded AC Microgrids With Arbitrary Topology," IEEE Trans Ind Electron, vol. 64, no. 8, pp. 67066713, Aug. 2017.

[114] K. Yu, Q. Ai, S. Wang, J. Ni, and T. Lv, "Analysis and Optimization of Droop Controller for Microgrid System Based on Small-Signal Dynamic Model," IEEE Trans Smart Grid, vol. 7, no. 2, pp. 1-11, 2015.

[115] F. J. Lin, K. C. Lu, and B. H. Yang, "Recurrent Fuzzy Cerebellar Model Articulation Neural Network Based Power Control of a Single-Stage Three-Phase Grid-Connected Photovoltaic System during Grid Faults," IEEE Trans Ind Electron, vol. 64, no. 2, pp. 1258-1268, 2017.

[116] M. A. Hannan, J. A. Ali, A. Mohamed, and M. N. Uddin, "A 
Random Forest Regression Based Space Vector PWM Inverter Controller for the Induction Motor Drive," IEEE Trans Ind Electron, vol. 64, no. 4, pp. 2689-2699, Apr. 2017.

[117] Q. N. Trinh, F. H. Choo, and P. Wang, "Control Strategy to Eliminate Impact of Voltage Measurement Errors on Grid Current Performance of Three-Phase Grid-Connected Inverters," IEEE Trans Ind Electron, vol. 64, no. 9, pp. 7508-7519, 2017

[118] S. Swain and B. Subudhi, "A New grid synchronisation scheme for a three-phase PV system using self-tuning filtering approach," IET Gener Transm Distrib, vol. 11, no. 14, pp. 3557-3567, 2017.

[119] F. M. Albatsh, S. Mekhilef, S. Ahmad, and H. Mokhlis, "Fuzzy Logic Based UPFC and Laboratory Prototype Validation for Dynamic Power Flow Control in Transmission Lines," IEEE Trans Ind Electron, vol. 64, no. 12, pp. 1-1, 2017.

[120] Z. Li, C. Zang, P. Zeng, H. Yu, S. Li, and J. Bian, "Control of a Grid-Forming Inverter Based on Sliding-Mode and Mixed $\mathrm{H} 2 / \mathrm{H} \infty$ Control," IEEE Trans Ind Electron, vol. 64, no. 5, pp. 3862-3872, May 2017.

[121] F. Sebaaly, H. Vahedi, H. Y. Kanaan, N. Moubayed, and K. AlHaddad, "Sliding Mode Fixed Frequency Current Controller Design for Grid-Connected NPC Inverter," IEEE J Emerg Sel Top Power Electron, vol. 4, no. 4, pp. 1397-1405, 2016.

[122] R. Errouissi, A. Al-Durra, and S. M. Muyeen, "Offset-free feedback linearisation control of a three-phase grid-connected photovoltaic system," IET Power Electron, vol. 9, no. 9, pp. 19331942, 2016.

[123] M. P. S. Gryning, Q. Wu, M. Blanke, H. H. Niemann, and K. P. H. Andersen, "Wind turbine inverter robust loop-shaping control subject to grid interaction effects," IEEE Trans Sustain Energy, vol. 7, no. 1, pp. 41-50, 2016.

[124] X. Fu and S. Li, "Control of Single-Phase Grid-Connected Converters with LCL Filters Using Recurrent Neural Network and Conventional Control Methods," IEEE Trans Power Electron, vol. 31, no. 7, pp. 5354-5364, 2016.

[125] C. Bhattacharjee and B. K. Roy, "Advanced fuzzy power extraction control of wind energy conversion system for power quality improvement in a grid tied hybrid generation system," IET Gener Transm Distrib, vol. 10, no. 5, pp. 1179-1189, 2016.

[126] O. Aguilar, R. Tapia, A. Valderrabano, and H. Minor, "Design and performance comparison of PI and adaptive current controllers for a WECS," IEEE Lat Am Trans, vol. 13, no. 5, pp. 1361-1368, 2015.

[127] M. A. Hannan, Z. A. Ghani, A. Mohamed, and M. N. Uddin, "Real-Time Testing of a Fuzzy-Logic-Controller-Based GridConnected Photovoltaic Inverter System," IEEE Trans Ind Appl, vol. 51, no. 6, pp. 4775-4784, Nov. 2015.

[128] A. I. Alolah, H. M. Hasanien, S. M. Muyeen, and T. A. Taj, "Transient stability enhancement of a grid-connected wind farm using an adaptive neuro-fuzzy controlled-flywheel energy storage system," IET Renew Power Gener, vol. 9, no. 7, pp. 792-800, 2015.

[129] S. Ozdemir, O. Kaplan, I. Sefa, and N. Altin, "Fuzzy PI controlled inverter for grid interactive renewable energy systems," IET Renew Power Gener, vol. 9, no. 7, pp. 729-738, Sep. 2015.

[130] H. Bevrani, P. R. Daneshmand, P. Babahajyani, Y. Mitani, and T. Hiyama, "Intelligent LFC concerning high penetration of wind power: Synthesis and real-time application," IEEE Trans Sustain Energy, vol. 5, no. 2, pp. 655-662, 2014.

[131] R. F. Bastos, C. R. Aguiar, A. F. Q. Gonçalves, and R. Q. Machado, "An Intelligent Control System Used to Improve Energy Production From Alternative Sources With DC/DC Integration," IEEE Trans Smart Grid, vol. 5, no. 5, pp. 2486-2495, 2014.

[132] B. N. Alajmi, K. H. Ahmed, G. P. Adam, and B. W. Williams, "Single-Phase Single-Stage Transformer less Grid-Connected PV System," IEEE Trans Power Electron, vol. 28, no. 6, pp. 2664 2676, Jun. 2013

[133] M. Singh and A. Chandra, "Real-time implementation of ANFIS control for renewable interfacing inverter in $3 \mathrm{P} 4 \mathrm{~W}$ distribution network," IEEE Trans Ind Electron, vol. 60, no. 1, pp. 121-128, 2013.

[134] H. Bevrani, F. Habibi, P. Babahajyani, M. Watanabe, and Y. Mitani, "Intelligent frequency control in an AC microgrid: Online PSO-based fuzzy tuning approach," IEEE Trans Smart Grid, vol. 3, no. 4, pp. 1935-1944, 2012.

[135] M. Azzouz, A. -1. Elshafei, and H. Emara, "Evaluation of fuzzybased maximum power-tracking in wind energy conversion systems," IET Renew Power Gener, vol. 5, no. 6, p. 422, 2011.

[136] T. Chaiyatham and I. Ngamroo, "Improvement of power system transient stability by PV farm with fuzzy gain scheduling of PID controller," IEEE Syst J, vol. 11, no. 3, pp. 1684-1691, 2017.

[137] N. Mahmud, A. Zahedi, and A. Mahmud, "A Cooperative Operation of Novel PV Inverter Control Scheme and Storage Energy Management System Based on ANFIS for Voltage Regulation of Grid-Tied PV System," IEEE Trans Ind Informatics, vol. 13, no. 5, pp. 2657-2668, Oct. 2017.

[138] F.-J. Lin, H.-C. Chiang, J.-K. Chang, and Y.-R. Chang, "Intelligent wind power smoothing control with BESS," IET Renew Power Gener, vol. 11, no. 2, pp. 398-407, 2017.

[139] Y. Hoon, M. A. M. Radzi, M. K. Hassan, and N. F. Mailah, "Neutral-point voltage deviation control for three-level inverterbased shunt active power filter with fuzzy-based dwell time allocation," IET Power Electron, vol. 10, no. 4, pp. 429-441, 2017.

[140] H. Nian, Y. Shen, H. Yang, and Y. Quan, "Flexible Grid Connection Technique of Voltage-Source Inverter Under Unbalanced Grid Conditions Based on Direct Power Control," IEEE Trans Ind Appl, vol. 51, no. 5, pp. 4041-4050, 2015

[141] S. Bayhan, M. Trabelsi, H. Abu-Rub, and M. Malinowski, "Finite-Control-Set Model-Predictive Control for a Quasi-ZSource Four-Leg Inverter Under Unbalanced Load Condition," IEEE Trans Ind Electron, vol. 64, no. 4, pp. 2560-2569, Apr. 2017.

[142] A. Tavakoli, M. Negnevitsky, and K. M. Muttaqi, “A Decentralized Model Predictive Control for Operation of Multiple Distributed Generators in an Islanded Mode," IEEE Trans Ind Appl, vol. 53, no. 2, pp. 1466-1475, Mar. 2017.

[143] M. Nauman and A. Hasan, "Efficient Implicit Model-Predictive Control of a Three-Phase Inverter With an Output LC Filter," IEEE Trans Power Electron, vol. 31, no. 9, pp. 6075-6078, Sep. 2016.

[144] Y. Liu, B. Ge, H. Abu-Rub, H. Sun, F. Z. Peng, and Y. Xue, "Model Predictive Direct Power Control for Active Power Decoupled Single-Phase Quasi-Z -Source Inverter," IEEE Trans Ind Informatics, vol. 12, no. 4, pp. 1550-1559, Aug. 2016.

[145] V. Yaramasu, B. Wu, M. Rivera, and J. Rodriguez, "A New Power Conversion System for Megawatt PMSG Wind Turbines Using Four-Level Converters and a Simple Control Scheme Based on Two-Step Model Predictive Strategy\&\#x2014;Part I: Modeling and Theoretical Analysis," IEEE J Emerg Sel Top Power Electron, vol. 2, no. 1, pp. 3-13, Mar. 2014

[146] S. Chowdhury, P. W. Wheeler, C. Gerada, and C. Patel, "Model Predictive Control for a Dual-Active Bridge Inverter With a Floating Bridge," IEEE Trans Ind Electron, vol. 63, no. 9, pp. 5558-5568, Sep. 2016.

[147] T. J. Besselmann, S. Van de moortel, S. Almer, P. Jorg, and H. J. Ferreau, "Model Predictive Control in the Multi-Megawatt Range," IEEE Trans Ind Electron, vol. 63, no. 7, pp. 4641-4648, Jul. 2016.

[148] H. Zhao, Q. Wu, Q. Guo, H. Sun, and Y. Xue, "Optimal active power control of a wind farm equipped with energy storage system based on distributed model predictive control," IET Gener Transm Distrib, vol. 10, no. 3, pp. 669-677, Feb. 2016.

[149] V. Yaramasu, B. Wu, and J. Chen, "Model-Predictive Control of Grid-Tied Four-Level Diode-Clamped Inverters for HighPower Wind Energy Conversion Systems," IEEE Trans Power Electron, vol. 29, no. 6, pp. 2861-2873, Jun. 2014.

[150] S. Bayhan, H. Abu-Rub, and R. S. Balog, "Model Predictive Control of Quasi-Z-Source Four-Leg Inverter," IEEE Trans Ind Electron, vol. 63, no. 7, pp. 4506-4516, Jul. 2016.

[151] D. Zhou, J. Zhao, and Y. Liu, "Predictive Torque Control Scheme for Three-Phase Four-Switch Inverter-Fed Induction Motor Drives With DC-Link Voltages Offset Suppression," IEEE Trans Power Electron, vol. 30, no. 6, pp. 3309-3318, Jun. 2015.

[152] M. Mosa, R. S. Balog, and H. Abu-Rub, "High-performance predictive control of quasi-impedance source inverter," IEEE Trans Power Electron, vol. 32, no. 4, pp. 3251-3262, 2017.

[153] H. Gao, B. Wu, D. D. Xu, M. Pande, and R. P. Aguilera, "Common-Mode-Voltage-Reduced Model-Predictive Control Scheme for Current-Source-Converter-Fed Induction Motor Drives," IEEE Trans Power Electron, vol. 32, no. 6, pp. 48914904, 2017.

[154] A. Ayad, P. Karamanakos, and R. Kennel, "Direct Model Predictive Current Control Strategy of Quasi-Z-Source Inverters," IEEE Trans Power Electron, vol. 32, no. 7, pp. 5786-5801, Jul. 2017.

[155] R. Errouissi, A. Al-Durra, and S. M. Muyeen, "Design and implementation of a nonlinear pi predictive controller for a gridtied photovoltaic inverter," IEEE Trans Ind Electron, vol. 64, no. 2, pp. 1241-1250, 2017. 
[156] X. Li, H. Zhang, M. B. Shadmand, and R. S. Balog, "Model Predictive Control of a Voltage-Source Inverter with Seamless Transition between Islanded and Grid-Connected Operations," IEEE Trans Ind Electron, vol. 64, no. 10, pp. 7906-7918, 2017.

[157] W. Hua, W. Huang, and F. Yu, "Improved model-predictiveflux-control strategy for three-phase four-switch inverter-fed fluxreversal permanent magnet machine drives," IET Electr Power Appl, vol. 11, no. 5, pp. 717-728, 2017.

[158] I. Kim, R. Chan, and S. Kwak, "Model Predictive Control Method for CHB Multi-Level Inverter with Reduced Calculation Complexity and Fast Dynamics," IET Electr Power Appl, vol. 11, no. 5, pp. 784-792, 2017

[159] M. B. Shadmand, X. Li, R. S. Balog, and H. Abu Rub, "Constrained decoupled power predictive controller for a singlephase grid-tied inverter," IET Renew Power Gener, vol. 11, no. 5, pp. 659-668, 2017

[160] S.-Y. Park and S. Kwak, "Comparative study of three model predictive current control methods with two vectors for threephase DC/AC VSIs," IET Electr Power Appl, vol. 11, no. 7, pp. 1284-1297, 2017.

[161] X. Xing, C. Zhang, J. He, A. Chen, and Z. Zhang, "Model predictive control for parallel three-level T-type grid-connected inverters in renewable power generations," IET Renew Power Gener, vol. 11, no. 11, pp. 1353-1363, 2017.

[162] R. Baidya, R. Aguilera, P. Acuna, S. Vazquez, and H. D. Mouton, "Multistep Model Predictive Control for Cascaded H-Bridge Inverters: Formulation and Analysis," IEEE Trans Power Electron, vol. 33, no. 1, pp. 1-1, 2017.

[163] X. Zhang, Y. Wang, C. Yu, L. Guo, and R. Cao, "Hysteresis model predictive control for high-power grid-connected inverters with output LCL filter," IEEE Trans Ind Electron, vol. 63, no. 1, pp. 246-256, 2016

[164] K. T. Tan, B. Sivaneasan, X. Y. Peng, and P. L. So, "Control and Operation of a DC Grid-Based Wind Power Generation System in a Microgrid," IEEE Trans Energy Convers, vol. 31, no. 2, pp. 496-505, 2016.

[165] S. Sajadian and R. Ahmadi, "Model Predictive Based Maximum Power Point Tracking for Grid-tied Photovoltaic Applications Using a Z-Source Inverter," IEEE Trans Power Electron, vol. 8993, no. c, pp. 1-1, 2016.

[166] M. Trabelsi, S. Bayhan, K. A. Ghazi, H. Abu-Rub, and L. BenBrahim, "Finite-Control-Set Model Predictive Control for GridConnected Packed-U-Cells Multilevel Inverter," IEEE Trans Ind Electron, vol. 63, no. 11, pp. 7286-7295, Nov. 2016.

[167] A. Bakeer, M. A. Ismeil, and M. Orabi, "A Powerful Finite Control Set-Model Predictive Control Algorithm for Quasi ZSource Inverter," IEEE Trans Ind Informatics, vol. 12, no. 4, pp. 1371-1379, 2016.

[168] X. Xiao, Y. Zhang, J. Wang, and H. Du, “An Improved Model Predictive Control Scheme for the PWM Rectifier-Inverter System Based on Power-Balancing Mechanism," IEEE Trans Ind Electron, vol. 63, no. 8, pp. 5197-5208, 2016.

[169] L. Guo, X. Zhang, S. Yang, Z. Xie, and R. Cao, "A Model Predictive Control-Based Common-Mode Voltage Suppression Strategy for Voltage-Source Inverter," IEEE Trans Ind Electron, vol. 63, no. 10, pp. 6115-6125, 2016.

[170] S. Kwak and S. Mun, "Model Predictive Control Methods to Reduce Common-Mode Voltage for Three-Phase Voltage Source Inverters," IEEE Trans Power Electron, vol. 30, no. 9, pp. 5019 5035, 2015.

[171] R. P. Aguilera and D. E. Quevedo, "Predictive control of power converters: Designs with guaranteed performance," IEEE Trans Ind Informatics, vol. 11, no. 1, pp. 53-63, 2015.

[172] L. Yin, Z. Zhao, T. Lu, S. Yang, and G. Zou, "An improved DC-link voltage fast control scheme for a PWM rectifier-inverter system," IEEE Trans Ind Appl, vol. 50, no. 1, pp. 462-473, 2014.
[173] J. R. Fischer, S. A. Gonzalez, M. A. Herran, M. G. Judewicz, and D. O. Carrica, "Calculation-delay tolerant predictive current controller for three-phase inverters," IEEE Trans Ind Informatics, vol. 10 , no. 1, pp. 233-242, 2014.

[174] V. Yaramasu and B. Wu, "Model predictive decoupled active and reactive power control for high-power grid-connected fourlevel diode-clamped inverters," IEEE Trans Ind Electron, vol. 61, no. 7, pp. 3407-3416, 2014.

[175] S. K. Haghighian, S. Tohidi, M. R. Feyzi, and M. Sabahi, "Design and analysis of a novel SEPIC-based multi-input DC/DC converter," IET Power Electron, vol. 10, no. 12, pp. 1393-1402, 2017.

[176] F. Kardan, R. Alizadeh, and M. R. Banaei, "A new Three Input DC/DC Converter for Hybrid PV/FC/Battery Applications," IEEE J Emerg Sel Top Power Electron, vol. 5, no. 4, pp. 1771-1778, 2017.

[177] S. Dusmez, S. Member, X. Li, S. Member, B. Akin, and S. Member, "A New Multiinput Three-Level DC / DC Converter," IEEE Trans Power Electron, vol. 31, no. 2, pp. 1230-1240, 2016.

[178] V. Michal, "Optimal peak-efficiency control of the CMOS interleaved multi-phase step-down DC-DC Converter with segmented power stage," IET Power Electron, vol. 9, no. 11, pp. 2223-2228, 2016.

[179] H. Zhu, D. Zhang, H. S. Athab, B. Wu, and Y. Gu, "PV isolated three-port converter and energy-balancing control method for PVbattery power supply applications," IEEE Trans Ind Electron, vol. 62, no. 6, pp. 3595-3606, 2015.

[180] X. Sun, Y. Zhou, W. Wang, B. Wang, and Z. Zhang, "Alternative source-port-tolerant series-connected double-input DC-DC converter," IEEE Trans Power Electron, vol. 30, no. 5, pp. 2733-2742, 2015.

[181] M. Leijon, S. K. Kottayil, D. E. Soman, and R. Krishna, "Pulse delay control for capacitor voltage balancing in a three-level boost neutral point clamped inverter," IET Power Electron, vol. 8, no. 2, pp. 268-277, 2015 .

[182] D. Fulwani, S. Singh, and V. Kumar, "Robust sliding-mode control of dc/dc boost converter feeding a constant power load," IET Power Electron, vol. 8, no. 7, pp. 1230-1237, 2015.

[183] M. R. Banaei, H. Ardi, R. Alizadeh, and A. Farakhor, "Nonisolated multi-input-single-output DC/DC converter for photovoltaic power generation systems," IET Power Electron, vol. 7, no. 11, pp. 2806-2816, 2014.

[184] D. Yang, M. Yang, and X. Ruan, "One-cycle control for a double-input DC/DC converter," IEEE Trans Power Electron, vol. 27, no. 11, pp. 4646-4655, 2012.

[185] A. A. Boora, F. Zare, and A. Ghosh, "Multi-output buck-boost converter with enhanced dynamic response to load and input voltage changes," IET Power Electron, vol. 4, no. 2, p. 194, 2011.

[186] A. Kwasinski, "Quantitative Evaluation of DC Microgrids Availability: Effects of System Architecture and Converter Topology Design Choices," IEEE Trans Power Electron, vol. 26, no. 3, pp. 835-851, 2011.

[187] T. L. Vandoorn, B. Meersman, L. Degroote, B. Renders, and L. Vandevelde, "A control strategy for islanded microgrids with DClink voltage control," IEEE Trans Power Deliv, vol. 26, no. 2, pp. 703-713, 2011

[188] Zhijun Qian, O. Abdel-Rahman, H. Al-Atrash, and I. Batarseh, "Modeling and Control of Three-Port DC/DC Converter Interface for Satellite Applications," IEEE Trans Power Electron, vol. 25, no. 3, pp. 637-649, Mar. 2010.

[189] Y. Li, X. Ruan, S. Member, D. Yang, F. Liu, and C. K. Tse, "Synthesis of Multiple-Input DC / DC Converters," IEEE Trans Power Electron, vol. 25, no. 9, pp. 2372-2385, 2010.

[190] A. Kwasinski, "Identification of Feasible Topologies for Multiple-Input DC - DC Converters," IEEE Trans Power Deliv, vol. 24, no. 3, pp. 856-861, 2009. 